\title{
Monogenic Forms of DSD: An Update
}

\author{
Kenneth McElreavey Anu Bashamboo \\ Human Developmental Genetics, Institut Pasteur, Paris, France
}

\author{
Keywords \\ Disorders/differences of sex development · Monogenic \\ disorders - Gonadal dysgenesis
}

\begin{abstract}
Background: DSD encompass a wide range of pathologies that impact gonad formation, development, and function in both $46, X X$ and $46, X Y$ individuals. The majority of these conditions are considered to be monogenic, although the expression of the phenotype may be influenced by genetic modifiers. Although considered monogenic, establishing the genetic etiology in DSD has been difficult compared to other congenital disorders for a number of reasons including the absence of family cases for classical genetic association studies and the lack of evolutionary conservation of key genetic factors involved in gonad formation. In recent years, the widespread use of genomic sequencing technologies has resulted in multiple genes being identified and proposed as novel monogenic causes of $46, X X$ and/or $46, X Y$ DSD. Summary: In this review, we will focus on the main genomic findings of recent years, which consists of new candidate genes or loci for DSD as well as new reproductive phenotypes associated with genes that are well established to cause DSD. For each gene or loci, we summarize the data that are currently available in favor of or against a role for these genes in DSD or the contribution of genomic variants within well-established genes to a new reproductive phenotype. Key Messages: Based on this analysis, we propose a
\end{abstract}

karger@karger.com www.karger.com/hrp

Karger"
(C) 2021 The Author(s)

Published by S. Karger AG, Basel

This article is licensed under the Creative Commons Attribution 4.0 International License (CC BY) (http://www.karger.com/Services/ OpenAccessLicense). Usage, derivative works and distribution are permitted provided that proper credit is given to the author and the original publisher. series of recommendations that should aid the interpretation of genomic data and ultimately help to improve the accuracy and yield genetic diagnosis of DSD.

(C) 2021 The Author(s).

Published by S. Karger AG, Basel

\section{Introduction}

Disorders/differences in sex development (DSD) are defined as congenital conditions with discordant development of chromosomal and gonadal/anatomical sex and cover a wide range of phenotypes that involve the endocrine and reproductive systems [1-3]. These pathologies are particularly challenging in terms of the clinical diagnosis, genetic etiology, patient management, and predicting long-term outcomes. The diagnosis of DSD is made either during fetal life, at birth, in the first months of life, or at puberty as these phenotypes can evolve throughout the lifetime of an individual [1-4]. Although a genetic cause is suspected in most cases of DSD, accurately identifying the causal variant has been historically challenging $[5,6]$. The most problematic phenotypes are those associated with either very early gonad formation or development of the external genitalia with apparently normal gonad formation $[5,6]$. The former are often due to errors in sex determination (e.g., 46,XY gonadal dysgenesis [GD] or 46,XX ovotesticular DSD), a genetic program that unlike other developmental process is not well 
conserved in evolution even amongst mammals. For this reason, testing candidate genes from other model organisms is often not informative. Indeed, several genes, which when mutated in the human cause gonadal anomalies, do not cause a DSD phenotype in the mouse $[5,7,8]$. At the other end of the phenotypic spectrum are the mild phenotypes of hypospadias and/or cryptorchidism, where population studies indicate that a mixture of genetics and environment may be responsible for the majority of cases [9-11].

Changes in sequencing technologies during the last decade have resulted in a rapid increase in the number of new genes proposed as candidates for monogenic forms of DSD $[5,6]$. Unbiased sequencing approaches such as exome sequencing, where all the coding genes in the genome are sequenced, have thrown up many surprises, including genes that would otherwise not have been considered to be involved in DSD, such as the RNA helicase DHX37 $[12,13]$. The other theme to emerge from largescale exome sequencing studies is the broadening of the range of phenotypes associated with what were considered to be well-characterized DSD genes such as WT1 and NR5A1 [14-16]. Advances in our understanding of the genetic etiology of DSD will continue as whole-genome sequencing rather than whole-exome sequencing becomes more widely available. This will inevitably lead to an emphasis on the contribution of regulatory variants to DSD, which will present a new set of challenges to establish causality. In this review, we will focus on genes that have recently been proposed to cause monogenic forms of DSD. We will assess the evidence in favor of, or against, the causality of these genes and provide a summary of the available data. A summary of these genes is listed in Tables 1-3. For many of these genes, the phenotypic variability is considerable. This often includes individuals carrying the same amino acid change in a DSD gene [5, $17,18]$. In this review, an important consideration is what we mean by the term monogenic. A monogenic phenotype is a phenotype produced by the effect of a single pair of genes or alleles. The genes/variants that are described here are considered to be monogenic causes of DSD (i.e., variants involving such genes have triggered DSD, and DSD would not have occurred in the absence of these variants). However, the phenotypic variability may well be due to other genomic variants or environmental influences on the regulatory pathways required for gonad formation and/or function. There are efforts underway to define the range of genetic variants that influence the DSD phenotype for a given individual, but caution is needed in the interpretation of these data. In the absence of any large-scale, unbiased, whole-genome-wide association studies, these proposed genetic modifiers remain unproven with no functional or statistical evidence to support a role in pathogenicity [19-21].

\section{6,XY DSD}

The majority of new genes that have recently been identified to cause DSD are mainly associated with either syndromic or nonsyndromic forms of $46, \mathrm{XY}$ GD $[5,6]$, the main reason being that GD is a well-defined DSD phenotype that permits a detailed cohort analysis. This subgroup of XY DSD is also considered to be monogenic with little or no known environmental influences on the development of the phenotype. This contrasts with milder 46,XY DSD phenotypes, which are considered multigenic with an environmental contribution and where the genetic components have proven difficult to identify [911]. Here, we will provide a background and update of the genes and variants involved that complements the information in Tables 1-3. Overviews on the genetic aspects of other well-established DSD genes that are a common cause of 46,XY DSD have been published recently including the $\mathrm{AR}, \mathrm{AMH}$ signaling, and disorders of androgen synthesis [22-25].

\section{CBX2}

The human Chromobox homolog 2 (CBX2) gene encodes a component of the polycomb (PcG) multiprotein complex. PcG proteins together with the counteracting trithorax (trxG) proteins control transcription throughout development via chromatin remodeling and/or histone modification. Disruption of $C b \times 2$ in mice results in male-to-female gonadal sex reversal [26]. These mice show a delay in appearance of genital ridges and formation of hypoplastic gonads in both the sexes. XY sex reversal caused by loss of $C b \times 2$ can be rescued by simultaneously deleting Wnt4 [27]. Available data indicate that during testis development, $\mathrm{Cbx} 2$ stabilizes the testis fate by blocking the upregulation of genes in the ovarian pathway [27]. In the human, only a single case with $46, \mathrm{XY}$ DSD has been reported to carry pathogenic variants in CBX2 [28]. The patient was a phenotypic female with complete lack of testis determination. She had bilateral ovaries and carried the biallelic variants, p.P98L (paternally inherited) and p.R443P (maternally inherited). Both of these CBX2 variants are absent in the general population (https://gnomad.broadinstitute.org/), and functional analysis indicated that they affect the biological activity 


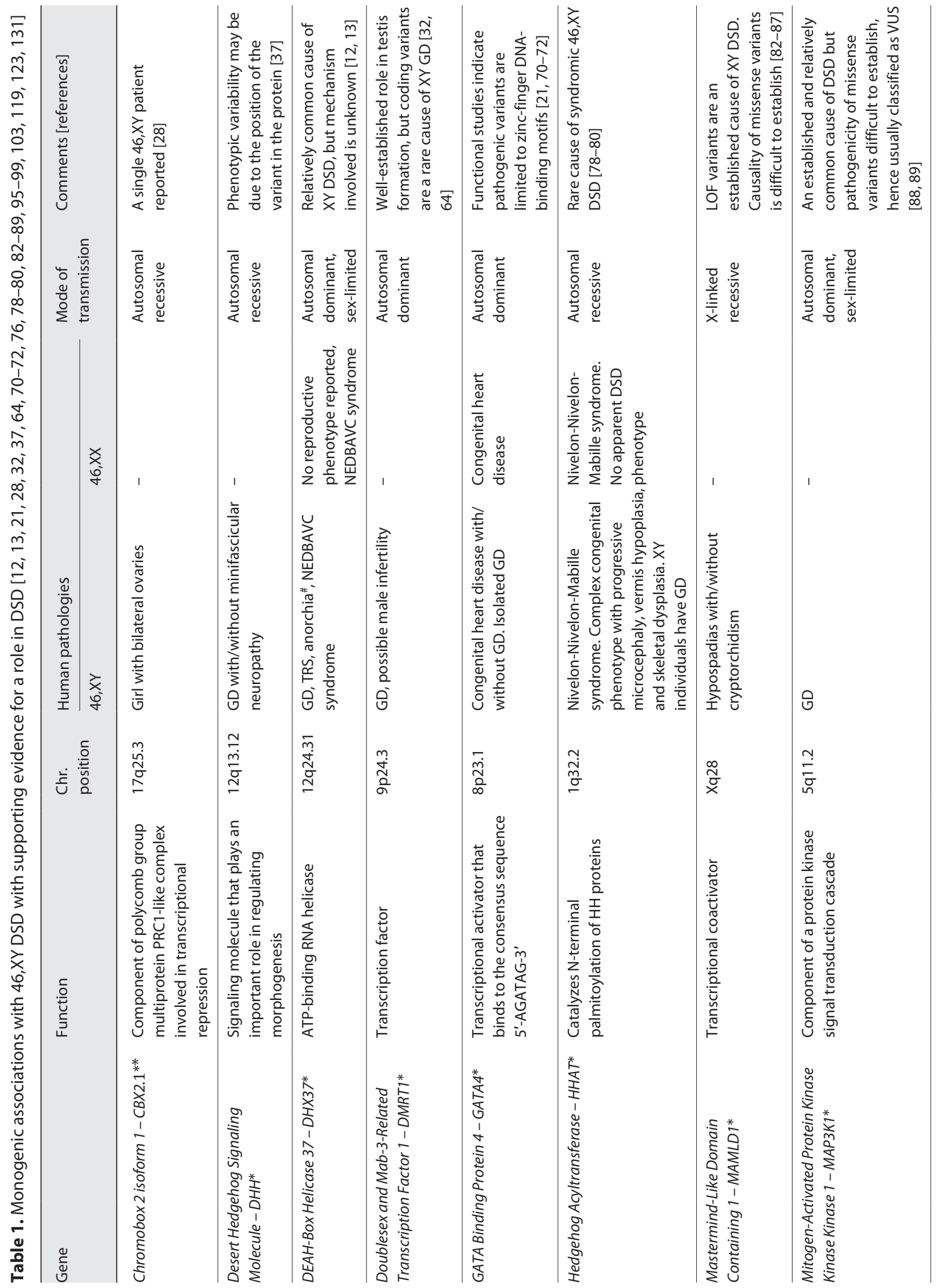




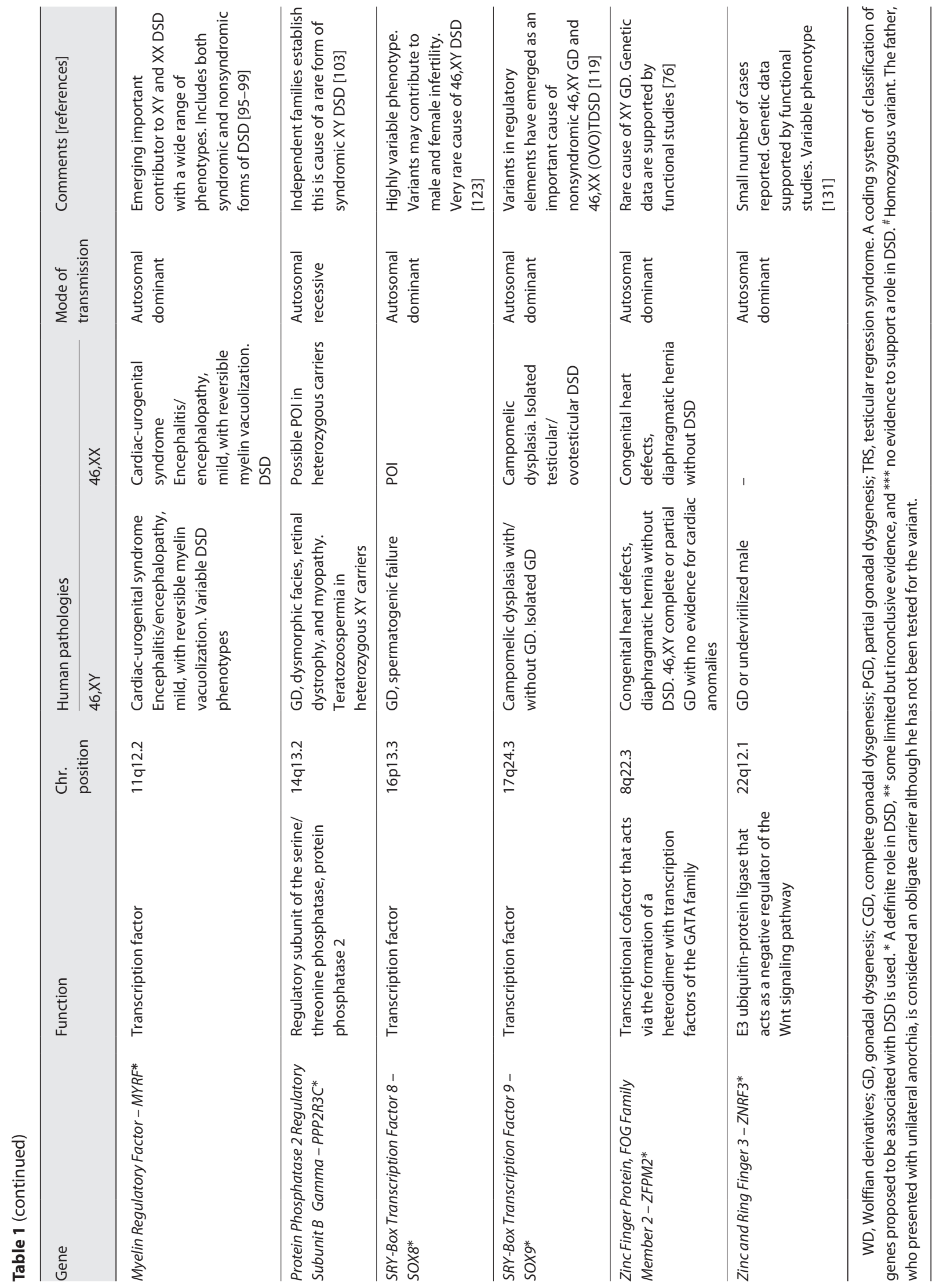









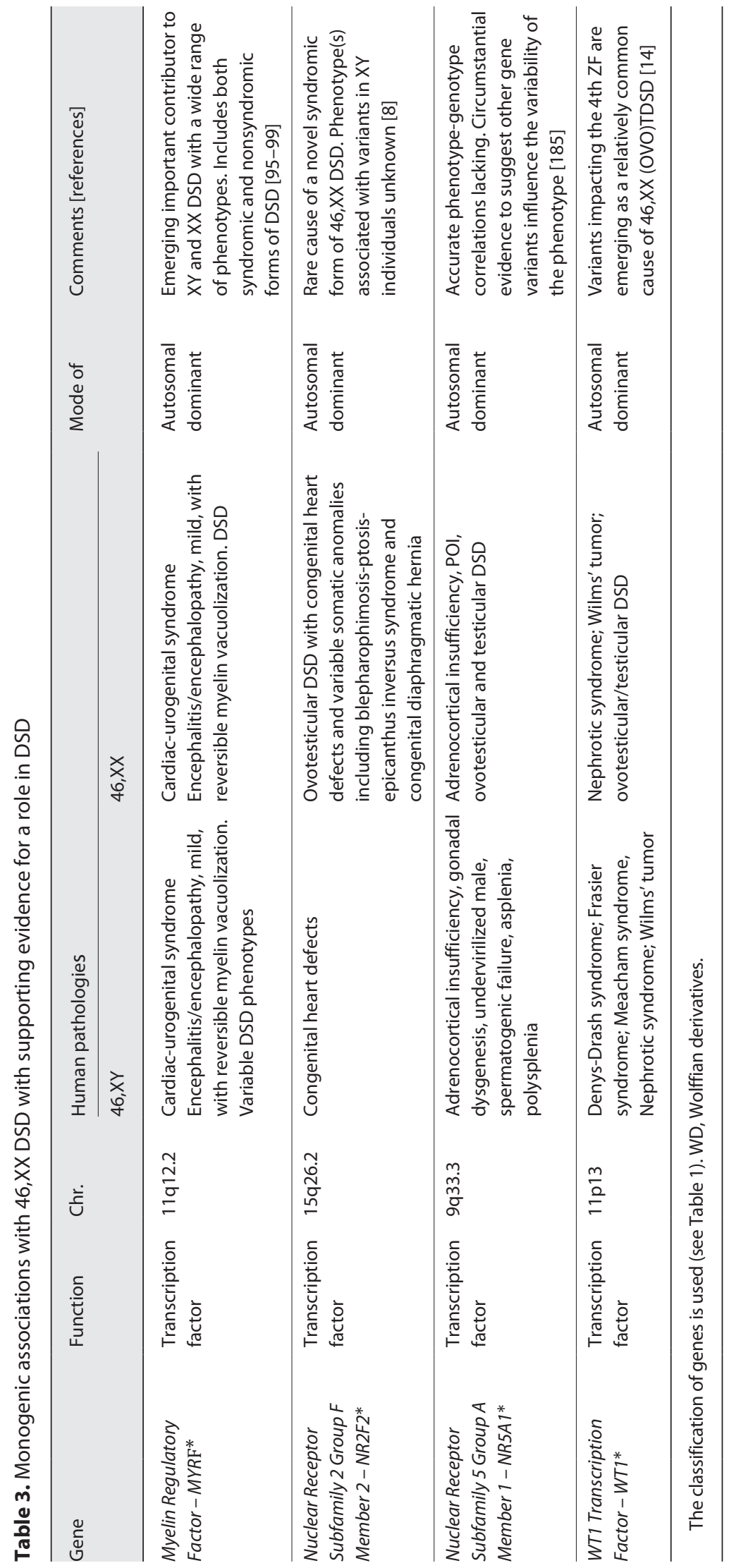

6 
of the protein (Table 1). Pathogenic variants in $\mathrm{CBX} 2$ causing XY DSD are very rare as other studies have failed to identify any causal variants in the gene [29-34].

An isoform of CBX2, termed CBX2.2, is a truncated form of the reference sequence CBX2.1. CBX2.2 has 211 amino acids, including only the chromodomain, compared with the reference CBX2.1 isoform which has 532 amino acids. CBX2.2 has been suggested to cause 46,XY DSD [35]. To support this, the authors identified two variants, a missense (p.Cys132Arg) variant and a complete loss-of-function (LOF) variant (p.Cys154fs). However, population genetics data indicate that the latter variant is carried by 1/125 African Americans (https://gnomad. broadinstitute.org/variant/17-77755771-CT C?dataset=gnomad_r2_1), including several XY males who are homozygous for the variant. This variant is carried by $12 \%$ of North African individuals (unpublished data). Consequently, this variant cannot be pathologic. A further analysis of population genetics datasets indicates that the CBX2.2 isoform has currently $23 \mathrm{LOF}$ variants (https://gnomad.broadinstitute.org/gene/ ENSG00000173894?dataset=gnomad_r2_1). Several of these LOF variants are present in the general populations at frequencies that are both inconsistent with CBX2.2 having a biological function and also exclude CBX2.2 as a cause of 46,XY DSD. The CBX2.2 isoform should therefore not be considered as a cause of 46,XY DSD (Table 2).

\section{$\mathrm{DHH}$}

The Hedgehog $(\mathrm{Hh})$ signaling pathway is important for gonadal development in mice and humans [36]. Hh proteins, including Desert Hedgehog $(\mathrm{DHH})$, are expressed as unprocessed preproproteins that undergo processing and autocatalytic cleavage. Following cleavage, the N-terminal fragment of $19 \mathrm{kDa}(\mathrm{HhN})$ retains all $\mathrm{Hh}$ signaling activity. $\mathrm{DHH}$, a product of Sertoli cells in the fetal testis, regulates the specification and formation of androgen producing fetal Leydig cells [36]. Biallelic variants of DHH have been described in patients with 46,XY GD with or without polyneuropathy. These patients are rare with less than 20 cases reported in the literature [37]. Why some patients present with both GD and polyneuropathy and others only with GD is unclear. However, functional studies suggest that variants which disrupt the $\mathrm{N}$-terminal fragment $\mathrm{HhN}$ are associated with GD and polyneuropathy, whereas those variants that effect the autoprocessing activity of DHH are associated only with GD [37].

One of the challenges created by large-scale exome sequencing studies of DSD cohorts is the interpretation of heterozygous variants of genes known to cause DSD in an autosomal recessive manner [30]. Heterozygous variants in DHH have been reported in 46,XY DSD and interpreted as variants of unknown or uncertain significance (VUS). Recently, functional analysis of these variants confirms that they are unlikely to be involved in the DSD phenotype and should therefore be considered likely benign [38].

\section{DHX37}

Two subgroups of DSD are the comparatively rare condition of 46,XY testicular regression syndrome (TRS) and anorchia. TRS is defined by a $46, \mathrm{XY}$ chromosome complement, ambiguous or atypical genitalia, anomalies of sexual duct formation, and absence of gonadal tissue on one or both sides [39-41]. Some boys with TRS are born with normal external genitalia but present with cryptorchidism. Boys with TRS are considered to have variable degrees of testicular determination with the loss of gonad tissue early in gestation, and the families of some patients with TRS also include other children with complete or partial 46,XY GD or agonadism $[42,43]$. Thus, both 46,XY GD and TRS are regarded as a continuum of phenotypes due to errors in testis determination and maintenance of gonadal tissue rather than distinct and unrelated DSD categories. The closely related phenotype of anorchia is defined by the absence of testicular tissue in a $46, \mathrm{XY}$ phenotypic male that may be unilateral or bilateral. However, since male-typical differentiation of the genital tract and the development of the external genitalia is dependent on the production of anti-Müllerian hormone $(\mathrm{AMH})$ and androgens, the testis must have been present at least up to the 16th week of gestation in men with anorchia.

An advantage of using unbiased genetic screens, such as exome or genome sequencing, is that they often reveal unexpected genetic associations with the phenotype. The discovery by us and others of frequent pathogenic variants in the RNA helicase DHX37 in association with $46, \mathrm{XY}$ GD or $46, \mathrm{XY}$ TRS is an excellent example $[12,13]$. RNA helicases, including DHX37, play prominent roles in ribosome biogenesis in eukaryotic cells by the recruitment or dissociation of ribosomal proteins or other binding factors [44-47]. The ribosome performs the essential function of translating mRNA into proteins [48]. Eukaryotic ribosome assembly is characterized by the sequential modular assembly of pre-ribosomal complexes. The human ribosome consists of ribonucleoprotein complexes with a small 40 S subunit (SSU) containing the $18 \mathrm{~S}$ rRNA chain and 33 proteins (RPS) and a large 60S subunit 


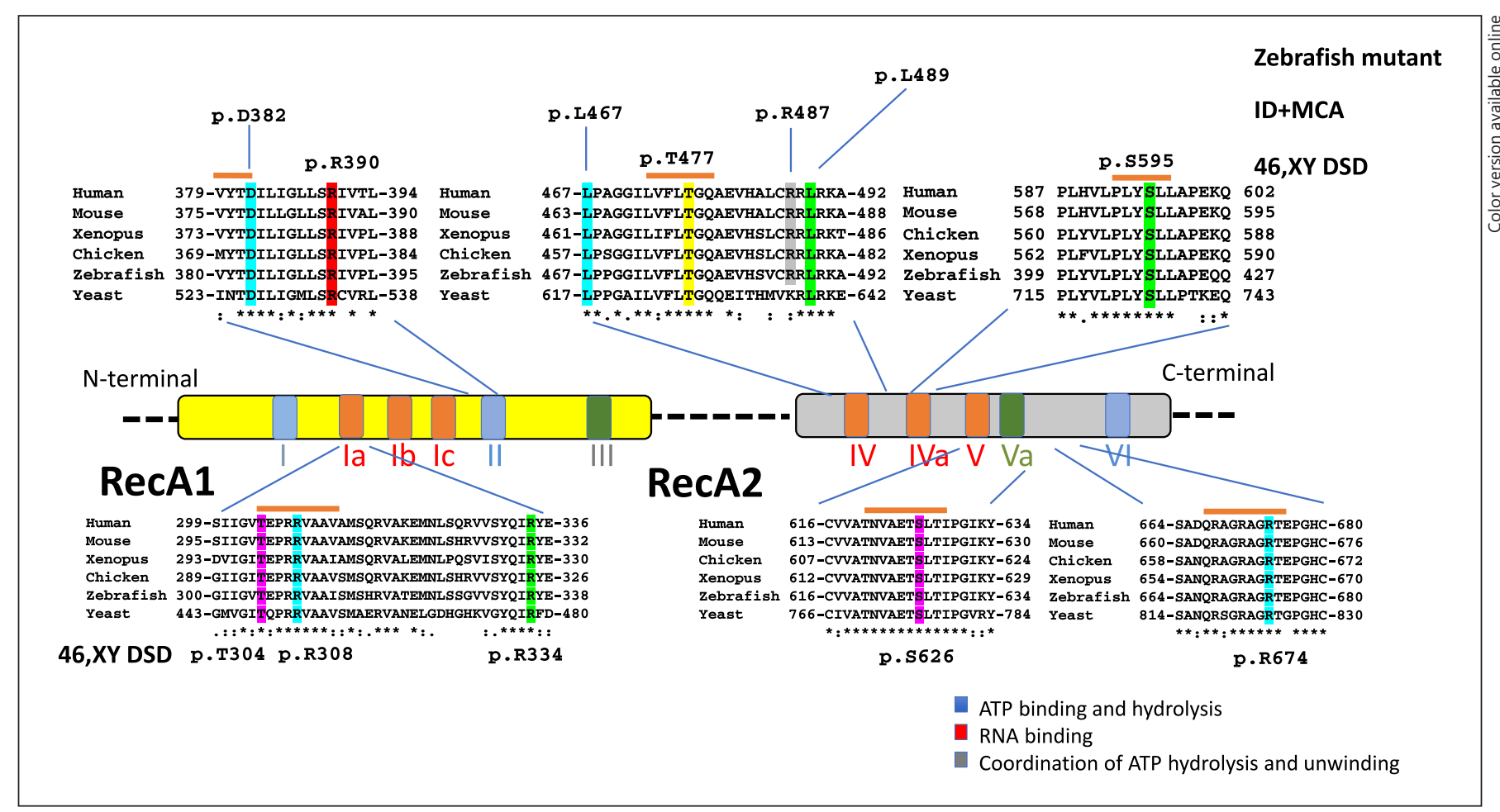

Fig. 1. Schematic representation of the RecA1 and RecA2 domains in DHX37, indicating the position and evolutionary conservation of residues that are associated with either 46,XY DSD, the NEDBAVC syndrome of ID and MCA, or the zebrafish tactile-evoked escape response mutant. The function of the motifs within each RecA domain is color-coded. ID, intellectual deficiency; MCA, multiple congenital anomalies.

(LSU) which has the 28S, 5S, and 5.8S rRNA chains and 47 proteins (RPL). Ribosome biogenesis is an intricate, complex, and coordinated process that takes place initially in the nucleolus and later in the cytoplasm [48].

DHX37 is a member of the DEAH family of RNA helicases, which share a similar protein core structure that consists of two flexibly linked RecA domains, within which are conserved sequence elements and conserved structural motifs. The two RecA-like domains of DHX37 use the conserved residues and motifs to both bind ATP (motifs I, II, III, Va, and VI) and target RNA sequences (motifs Ia, Ib, Ic, IV, IVa, and V [49, 50]; Fig. 1). This family of RNA helicases does not possess intrinsic substrate specificity and function by interacting with a large number of cofactors [50]. Although much of our knowledge on ribosome biogenesis and the role of DHX37 comes from studies in yeast, the function of DHX37 in ribosome biogenesis appears conserved in the human since the lack of the helicase in HeLa cells results in a reduction of the ribosome 40 S subunit [51]. The importance of DHX37 in this process is highlighted by the observation that in these cells, the absence of DHX37 triggers a surveillance pathway that leads to degradation of pre-ribosomal particles [51].

Variants in DHX37 have been reported to cause 46,XY GD, TRS, or anorchia $[12,13,32,52]$. A total of 36 individuals have been reported with 46,XY DSD associated with novel or very rare missense variants in DHX37 (Table 4; Fig. 1). Most variants are located within or immediately adjacent to highly conserved motifs within the RecA1 and RecA2 domains (Fig. 1). Pathogenic variants in DHX37 are an important cause of $46, \mathrm{XY}$ DSD, since $10-15 \%$ of all cases of nonsyndromic 46 , XY complete GD carry pathogenic DHX37 variants $[12,13,32,52]$. This frequency is similar to the prevalence of pathogenic variants in the SRY, MAP3K1, or NR5A1 genes. DHX37 variants also account for approximately $20 \%$ of all cases of TRS $[12,13,32,52]$. A striking feature of the variants causing DSD is that the affected amino acid residues fall within highly conserved functional motifs, and the residues themselves are conserved through to yeast. Indeed, almost half of all cases are due to a single amino acid vari- 
Table 4. Summary of DSD phenotypes associated with published DHX37 pathogenic variants

\begin{tabular}{|c|c|}
\hline $\begin{array}{l}\text { DHX37 variant } \\
\text { (patients, } n)\end{array}$ & XY DSD phenotypes \\
\hline p.T304 (3) & Female, GD + WD \\
\hline p.R308 (15) & $\begin{array}{l}\text { Female, GD; female, CGD + WD; female, PGD; } \\
\text { female } 46, X Y \text { DSD, virilized external genitalia; } \\
\text { male, TRS, micropenis, hypospadias + bilateral } \\
\text { cryptorchidism; male, TRS, micropenis, bilateral } \\
\text { cryptorchidism }\end{array}$ \\
\hline p.R334 (2) & $\begin{array}{l}\text { Female, GD + WD; male, TRS, micropenis, } \\
\text { bilateral cryptorchidism }\end{array}$ \\
\hline p.R390 (1) & Female, GD \\
\hline p.T477 (2) & $\begin{array}{l}\text { Female, GD; male, TRS micropenis, bilateral } \\
\text { cryptorchidism*; male, unilateral anorchia }\end{array}$ \\
\hline p.S595 (2) & Sibs - female, GD + WD; male TRS, micropenis \\
\hline p.S626 (1) & Male, TRS, micropenis, bilateral cryptorchidism \\
\hline p.R674 (9) & $\begin{array}{l}\text { Female CDG; female gonadal dysgenesis + WD; } \\
\text { male PGD + left testis; male TRS, micropenis }\end{array}$ \\
\hline p.G1030 (1) & Male, TRS, micropenis \\
\hline
\end{tabular}

WD, Wolffian ducts.

ant, p.R308Q, and there is no obvious genotype-phenotype correlation (Table 4). The gonadal phenotypes of individuals carrying the p.R308Q variant range from 46,XY complete or partial GD raised as female (6 individuals), $46, \mathrm{XY}$ DSD with atypical external genitalia raised as female (2 individuals), and 46,XY TRS with severe micropenis (with or without cryptorchidism and hypospadias) raised as male ( 9 individuals). Where the transmission of the variant p.R308Q can be established, 5 are de novo, 2 are maternally inherited, and 1 is paternally inherited. This is consistent with a sex-limited autosomal dominant mode of inheritance.

However, variants in DHX37 are also associated with other congenital anomalies with no apparent DSD [53, 54]. Compound heterozygous as well as de novo heterozygous missense variants in DHX37 cause a complex congenital developmental syndrome consisting of microcephaly, global developmental delay, seizures, facial dysmorphia, and kidney and cardiac anomalies as well as cortical atrophy. This syndrome, which has been termed NEDBAVC (neurodevelopmental disorder with brain anomalies and with or without vertebral or cardiac anomalies; OMIM 618731), has been described in 6 patients in association with homozygous missense variants ( $p$.
R487H and p.N419K), compound heterozygous missense variants (p.V731M/p.L467V and p.R93Q/p.E167A), or de novo missense variants (p.T1094M and p.D382G) [53, 54]. Three of the affected children were $46, \mathrm{XY}$ boys and three 46,XX girls. DSD was not reported in any of these 6 cases. Therefore, pathogenic missense variants in DHX37, even within the same RecA functional domain, may generate two distinct, nonoverlapping phenotypes. The DSD phenotype is limited to the formation and maintenance of Sertoli cells with no other reported developmental anomalies, whereas NEDBAVC is a complex syndromic form of developmental delay and/or intellectual disability with somatic anomalies but with apparent normal gonadal development. To date, missense variants shared by both $46, \mathrm{XY}$ DSD and NEDBAVC have not been reported.

Errors in the process of ribosome production, including defects in ribosomal proteins, rRNA processing, or ribosome assembly factors, lead to the development of a highly specific group of pathologies affecting selective organs or cell types that are collectively termed ribosomopathies $[55,56]$. The most studied ribosomopathies include Diamond-Blackfan anemia, Shwachman-Diamond syndrome, and Treacher Collins syndrome. DiamondBlackfan anemia is an autosomal dominant disorder which usually presents in early childhood as bone marrow failure $[55,57]$. Patients may also display a series of distinct congenital birth defects including skeletal abnormalities and cardiac and genitourinary malformations, together with an increased cancer susceptibility. DSD that is caused by pathogenic variants in the DHX37 gene constitute a new form of human ribosomopathy. Although the genetic causes of ribosomopathies have been known for over two decades, the mechanisms involved are poorly understood. Pathogenic variants are predicted to cause reduced ribosome assembly, and these pathologies reflect tissue/organ-specific needs for optimum protein production during development. This would impact on highly proliferative tissues such as hematopoiesis or skeletal development that require high protein synthesis. However, this does not adequately explain specific differences in the phenotypic presentation of these diseases. One possibility is that differing phenotypes reflect ribosome heterogeneity and functional specialization or that some of these factors could have acquired additional biological roles other than ribosome biogenesis.

Evidence in support of specific biological functions for DHX37, independent of its role in ribosome biogenesis, is indicated by both zebrafish studies and human genome-wide screens to identify factors that modulate hu- 
man T-cell function. Zebrafish, carrying a homozygous missense variant p.K489P in Dhx37 (Fig. 1) [58], exhibit changes in a tactile-evoked escape response. Wild-type fish turn and then swim away, whereas Dhx37 mutant fish show an atypical dorsal bend, followed by swimming. This behavior strongly resembles zebrafish embryos treated with strychnine, which blocks glycine receptors. The glycine receptor is a pentameric receptor composed of alpha and beta subunits that mediate postsynaptic inhibition in the spinal cord and other regions of the central nervous system. The abnormal motor response in mutants may be caused by a deficit in glycinergic synaptic transmission [58]. This was confirmed by both decreased expression levels of GlyR alpha and beta subunits in mutants. RNA immunoprecipitation assays demonstrated that zebrafish Dhx37 physically interacts with GlyR alpha subunit transcripts. Remarkably, the mutant fish exhibited no changes in ribosome biogenesis suggesting a specific neuronal function. In the human, CD8 T cells play essential roles in antitumor immune responses. Recently, genome-wide CRISPR screens using CD8 T cells in a cancer immunotherapy setting have identified DHX37 as an important regulator of antitumor effects [59]. Tumor-infiltrating lymphocytes lacking DHX37 have upregulated expression of specific genes in multiple immune response pathways [59]. This evidence suggests a link between ribosome biogenesis and tissue-specific gene expression profiles. How variants in DHX37 cause 46,XY DSD is unclear. This group of DSD patients is unique insofar that their underlying cause has no obvious link to known genetic pathways involved in human early testis formation (e.g., SRY/SOX9/NR5A1). This subgroup of 46,XY DSD may require a careful long-term clinical follow-up since patients with other forms of ribosomopathies have a 2.5to 8.5-fold higher risk to develop cancer throughout their life, and for certain cancer types, these risks can be up to 200-fold higher [60].

\section{DMRT1}

DMRT1 and its orthologs play essentials roles in sex determination and differentiation in many animals [61]. In mice, Dmrt1 is not required for testis determination; however, its continuous expression in the adult testis is required to maintain organ identity because forced attenuation of Dmrtl expression in adult testis results in transdifferentiation of the testis to an ovary [62]. In the human, deletions of terminal chromosome $9 \mathrm{p}$ which includes several genes as well as DMRT1 are associated with monosomy $9 \mathrm{p}$ syndrome. This is characterized by intellectual disability together with a distinctive series of so- matic anomalies, and in approximately $70 \%$ of $46, \mathrm{XY}$ individuals, anomalies of testis development are seen that range from a completely female phenotype to a male phenotype with hypospadias and/or cryptorchidism [63]. Pathogenic variants within the DMRT1 coding sequences are remarkably rare. Evidence to indicate that DMRT1 is a key player in human testis determination came through the identification of a de novo missense variant (p.R111G) in the functionally important DM-DNA-binding domain in a patient with 46,XY complete GD [65]. There were no other somatic anomalies in this healthy girl. In vitro studies indicated that lack of testis determination seen in this patient is due to a combination of haploinsufficiency and dominant negative activity. The only other DMRT1 variant that has been reported to cause 46,XY CGD is a novel de novo p.R80S variant, which is also located with the DM-DNA-binding domain. This variant is predicted to disrupt the interaction between DMRT1 and the minor groove of the DNA. Pathogenic variants of DMRT1 have not been reported in other large-scale exome sequencing studies of DSD cohorts (e.g., [30, 34]). One reason why pathogenic variants are rare is that to cause XY DSD, they must be located within a well-characterized functional domain and show dominant negative activity. A similar hypothesis has been suggested for the rarity of $S O X 8$ coding variants associated with XY DSD (see below).

\section{GATA4 and Partner ZFPM2 (FOG2)}

GATA4 is a zinc finger (ZF) transcription factor, characterized by presence of two conserved type IV ZF domains (amino acids 217-241 and 271-295) that interact with NR5A1 to regulate gene expression during testis determination and differentiation [65]. The key role of Gata4 in testis development has been known for some time. XY mice lacking Gata4 show partially descended small testis with irregular cords and are infertile [66]. Severe testicular dysgenesis is also observed in mice, which carry a p.Val217Gly mutation in the N-terminal ZF domain of the protein. This variant abolishes the physical interaction of Gata4 with its cofactor Zfpm2 (Fog2) [6668]. Pathogenic variants were first reported in GATA4 in association with only congenital heart disease (CHD), although a proportion of XY males carrying deletions of human 8p23.1 that includes the GATA4 gene have hypospadias and bilateral cryptorchidism [69]. We identified a familial case of 46,XY DSD and CHD that affected both 46,XX and 46,XY individuals [70]. The family carried a heterozygous missense mutation (p.Gly221Arg) located immediately adjacent to the mouse p.Val217Gly mutation in the $\mathrm{N}$-terminal ZF domain [70]. In functional 
Fig. 2. Schematic representation of GATA4 showing the main functional domains and in detail the amino acid composition of the $\mathrm{N}$-terminal ZF showing the position of variants established to cause 46,XY DSD. The valine residue that is mutated in mice which shows male-to-female sex reversal is highlighted in blue. Other variants associated with $46, \mathrm{XY}$ DSD are indicated. TAD, transcriptional activation domain; NLS, nuclear localization signal.

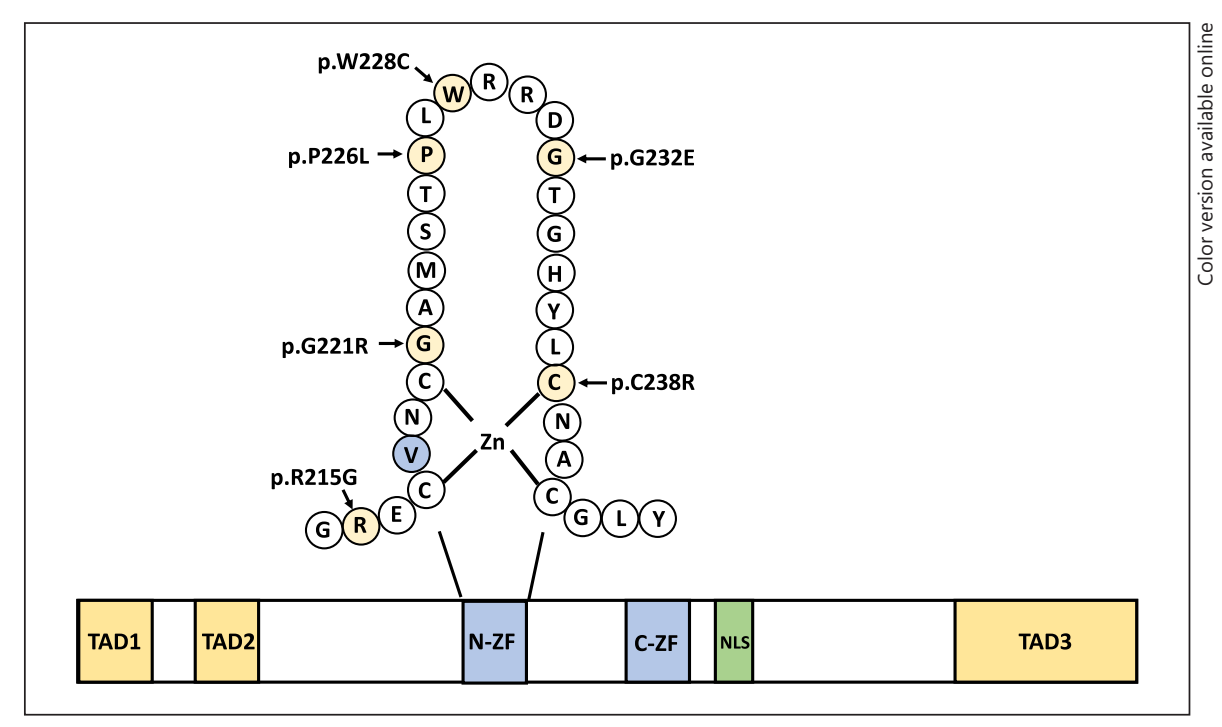

studies, the p.Gly221Arg variant failed to bind to DNA, did not transactivate AMH promoter, and lacked the ability to bind to ZFPM2. Other pathogenic missense variants in GATA4 have been reported since this initial publication, but they do appear to be very rare, are located within the $\mathrm{N}$-terminal $\mathrm{ZF}$, and may not involve $\mathrm{CHD}$ $([21,71,72]$ and unpublished) (Fig. 2). In large-scale exome sequencing studies, other variants have been found in 46,XY DSD patients in sequences flanking the $\mathrm{N}$-terminal ZF. Although these were initially classified as VUS [30], functional studies indicate that these have wild-type or near wild-type biological activity and are therefore benign [72]. Other missense variants, located in regions flanking the $\mathrm{N}$-terminal ZF domain, have been proposed to cause isolated hypospadias, and this needs to be confirmed by other studies [73].

ZFPM2 (FOG2) is a ZF cofactor that modulates the activity of GATA4 by binding to the N-terminal ZF [74]. There is considerable evidence in the literature to support a role for ZFPM2 in testis determination including the observation that XY $Z f p m 2^{-/-}$mice fail to develop testis [75]. Since ZFPM2 interacts with GATA4 through the GATA4 N-terminal ZF which harbors pathogenic variants, there is the possibility that variants of ZFPM2 may also cause 46,XY DSD. We identified a familial case of $46, \mathrm{XY}$ GD, where a heterozygous missense variant (p. S402R) segregated with the phenotype [76]. This variant is absent from gnomAD, and it abolishes the interaction of the ZFPM2 protein with GATA4. A second independent individual had a more complex ZFPM2 genotype with a de novo missense variant (p.R260Q) located within the $\mathrm{N}$-terminal ZF of the protein together with homo- zygosity for a rare missense variant p.M544I [76]. The ZFPM2 protein carrying these variants also showed altered biological activity. Pathogenic variants in ZFPM2 associated with DSD are also very rare. Although heterozygous variants ZFPM2 have been reported in large-scale exome sequencing studies, and classified as VUS, functional studies indicated that these variants are benign [ 30 , 72].

\section{HHAT}

The Hedgehog family of secreted signaling proteins plays a fundamental role during embryonic development, including early testis formation, by acting as morphogens to form concentration gradients for long-range and shortrange signaling [36]. Three Hedgehog proteins are expressed in vertebrates: Sonic (Shh), Indian (Ihh), and Desert (Dhh). The latter is secreted by Sertoli cells and functions as a commitment factor by inducing the formation of the Leydig cell lineage [36]. As described earlier, biallelic variants in DHH are associated with 46,XY GD [37]. Hedgehog acyltransferase (HHAT) is an ER-resident multipass membrane protein consisting of 10 transmembrane domains and 2 re-entrant loops [77]. It is a member of the membrane bound-O-acyltransferase (MBOAT) family of enzymes that catalyze the attachment of specific fatty acids to secreted proteins [77]. The palmitoylation of a member of the Hedgehog family, sonic hedgehog, is catalyzed by HHAT.

In a familial case of two sibs presenting with a complex phenotype including 46,XY DSD, exome sequencing identified a homozygous p.G287V missense variant in the MBOAT domain of HHAT [78]. One sib presented with 
chondrodysplasia, 46,XY GD, and multiple congenital anomalies (Nivelon-Nivelon-Mabille syndrome). The other sib was 46,XX with histologically normal ovaries and presented with a similar complex somatic phenotype. The variant disrupts the ability of the HHAT protein to palmitoylate DHH [78]. Hhat ${ }^{-/-}$mice display severely impaired development of fetal Leydig cells, Sertoli cells, and testis cords [78]. These data indicate that in the mouse, HHAT is required for the initiation of Leydig cell formation. Three other families with homozygous HHAT variants have been reported [79, 80]. Two 46,XX female sisters who presented with microcephaly and cerebellar vermis hypoplasia carried a homozygous missense variant (p.L257P) in the MBOAT domain HHAT [79]. There was no evidence of short stature, chondrodysplasia, or 46,XX GD in the sibs [79]. A second consanguineous family presented with multiple malformations in three pregnancies [80]. The proband presented with severe microphthalmia, microcephaly, skeletal dysplasia, facial dysmorphia, and 46,XY GD. The other two pregnancies also had similar somatic anomalies, but the karyotype is unknown. The proband carried a novel biallelic in-frame deletion (p.Thr122del) within the MOAT domain. A fourth family consisted of a girl with 46,XY GD and microcephaly, but with normal weight and height for her age and no evidence of other anomalies [80]. She carried a novel homozygous HHAT missense (p.N443K) variant, again located within the MBOAT domain. These data indicate that homozygous variants within the MBOAT domain of HHAT cause a very rare syndromic form of DSD in $46, \mathrm{XY}$ individuals together with microcephaly as the common feature and variable somatic anomalies.

\section{MAMLD1}

The mastermind-like domain-containing 1 (MAMLD1) gene, located on chromosome Xq28, is expressed together with NR5A1 in Sertoli and Leydig cells during early gonad formation [81]. The typical MAMLD1 phenotype is a 46,XY boy with hypospadias and cryptorchidism, bifid scrotum, and/or a micropenis. 46,XY complete GD has rarely been described [82, 83]. A single homozygous missense variant has been reported in association with 46,XX ovarian dysgenesis [84]. Most MAMLD1 variants that are classified as pathogenic are LOF variants (usually nonsense or frameshift variants). However, the interpretation of MAMLD1 missense variants associated with DSD has generated controversy. There are two elements to this controversy. The precise biological role of MAMLD1 in male genital development is unclear. Mice lacking Mamld1 show reduced expression of Leydig cell transcripts but otherwise have normal genitalia and are fertile [85]. Therefore, there is both an inability to model missense variants using the mouse model, and in the absence of a precisely known biological function, a functionally relevant biological assay is not available. The other aspect to consider is the population genetics. Some of the missense variants proposed to cause XY DSD are actually common polymorphisms in the general population. For example, the reported variants p.H322Q (p. H347Q) and p.V480A (p.V505A) carried by $6.5 \%$ and $17.8 \%$ of African/African Americans are polymorphisms [83]. They are both considered benign by ClinVar (ClinVar accession IDs 712305 and 804096). The recently published p.P334S variant, which is reported as likely pathogenic [86], is carried by $12 \%$ of Europeans, and it is therefore unlikely to be pathogenic. Further controversy concerning the contribution of MAMLD1 variants to DSD arises in familial cases, where the MAMLD1 variant does not always segregate with the phenotype [82]. To understand the contribution of MAMLD1 to DSD, there is a need to distinguish between those individuals carrying rare or novel LOF variants and those individuals who are carrying common polymorphisms that in all likelihood do not contribute to the phenotype. Functional analysis of potentially pathogenic missense variants has shown little difference between the wild-type and proteins carrying missense variants, but this is difficult to interpret in the absence of a known biological activity of MAMLD1 [87]. Population genetics data support a role for MAMLD1 variants causing DSD. In the general population, the MAMLD1 gene is only partially tolerant to LOF variants (https://gnomad.broadinstitute.org/gene/ ENSG00000013619?dataset=gnomad_r2_1) with a small number $(n=14)$ of LOF alleles reported in $>68,000$ alleles sequenced. A recent study and review of the literature by Li et al. [86] indicated that approximately one-third of MAMLD1 variants that cause XY DSD are LOF. This enrichment of MAMLD1 LOF variants in DSD cohorts compared with the general population is consistent with the hypothesis that variants which severely disrupt or abolish biological function are indeed responsible for DSD. However, in the absence of relevant and robust functional assays, the contribution of rare or novel missense variants to DSD remains to be determined, and these are likely to be continued to be classified as VUS in genomic studies.

\section{MAP3K1}

The mitogen-activated protein kinases (MAPKs) are activated through an evolutionarily conserved three-
12

Horm Res Paediatr

DOI: $10.1159 / 00052138$
McElreavey/Bashamboo 
component signal transduction cascade, composed of a mitogen-activated protein kinase kinase kinase 1 (MAP3K1), an MAP2K, and an MAPK. In the human, pathogenic variants in $M A P 3 K 1$ are an established cause of 46,XY DSD [88]. Precisely how MAP3K1 variants cause a failure of testis determination is unclear. Pathogenic variants are usually heterozygous and for the most part are not LOF. They are either missense or splice-site variants or in-frame deletions. A disruptive variant, such as nonsense or frameshift mutation, has not been reported, perhaps due to the fact that more severe variants of protein function may be embryonic lethal. Available data suggest that the missense variants associated with $46, \mathrm{XY}$ DSD may be subtle gain-of-function variants that result in the increased phosphorylation of the downstream MAPK targets $[88,89]$. Patients carrying MAP3K1 variants show no other apparent phenotypic anomalies other than $46, \mathrm{XY}$ GD [88]. In our experience, about $10 \%$ of $46, \mathrm{XY}$ GD cases harbor rare or novel variants in the $M A P 3 K 1$ gene that could potentially contribute to the phenotype. However, the MAP3K1 transcript is large ( $>7$ $\mathrm{kb}$ ) spanning 20 exons, and there are over 600 rare (MAF $<0.001$ ) or novel LOF or missense variants reported in the general population (https://gnomad.broadinstitute.org/ gene/ENSG00000095015?dataset=gnomad_r2_1). This makes the interpretation of a missense variant carried by an individual with DSD difficult, although there is some evidence to suggest that pathogenic variants cluster in specific functional domains of the protein [90]. However, in the absence of a robust and simple functional assay, the clinical interpretation of MAP $3 K 1$ variants associated with 46,XY DSD will remain a challenge and most will continue to be classified as VUS.

\section{MYRF}

Myelin regulatory factor (MYRF) is a large membraneassociated homo-trimeric protein that self-cleaves to release an N-terminal immunoglobulin-type Ndt80 domain for the DNA-binding [91-93]. The protein contains an intramolecular chaperone domain for trimerization and autoproteolysis in the central portion and a transmembrane domain in its carboxyterminal part that anchors the protein to the membrane of the endoplasmic reticulum (ER). Upon autocleavage, the MYRF N-terminal homo-trimer is released from the ER membrane and enters the nucleus to function as a transcription factor [91-93].

In the murine central nervous system, MYRF is specifically expressed by oligodendrocytes. MYRF was considered a myelin-specific transcription factor since con- ditional knockout of Myrf in oligodendrocyte precursors leads to widespread dysmyelination and severe neurological anomalies [94]. However, despite its name, MYRF is a pleiotropic transcription factor that is widely expressed during embryonic development including in the gonads. A broad range of phenotypes, including $46, \mathrm{XY}$ and $46, \mathrm{XX}$ DSD, are associated with pathogenic variants in the gene. Deleterious or LOF and often de novo variants in MYRF are associated with congenital diaphragmatic hernia $(\mathrm{CDH})$, cardiac anomalies including Scimitar syndrome, urogenital anomalies, and an encephalopathy syndrome [95-99]. The genitourinary anomalies in XY individuals include ambiguous external genitalia, hypospadias, horseshoe kidney, chordee, or cryptorchidism. A total of 14 46,XY individuals with syndromic phenotypes have been described to date, with 12 of them presenting with urogenital anomalies [96-99]. A further 2 cases of 46,XY boys have been described with only urogenital anomalies and no other somatic anomalies [96]. These two boys had micropenis, hypospadias, small testis, and cryptorchidism with low levels of testosterone and AMH [96]. Five affected 46,XX individuals have been described. Of these, one was reported to have no internal genital organs with a blind-ended vagina. A pair of 46,XX monozygotic twins were also reported who presented with small or absent ovaries and Mullerian duct aplasia with no other somatic anomalies [96]. These data indicate that variants in the MYRF gene can be considered a cause of either syndromic or nonsyndromic $46, \mathrm{XY}$ or $46, \mathrm{XX}$ DSD. There is no apparent relationship between the genotype and the phenotype; however, only a small number of cases have been reported to date, and this may evolve over time.

\section{PPP2R3C}

The protein phosphatase $2 \mathrm{~A}(\mathrm{PP} 2 \mathrm{~A})$ is one of the four protein phosphatases in eukaryotic cells that is responsible for the dephosphorylation of serine and threonine residues in proteins. PP2A forms several holoenzyme complexes [100]. The core enzyme consists of a catalytic C subunit (PP2Ac) and a regulatory A subunit that is associated with a regulatory $B$ subunit. The regulatory $B$ subunit can beclassified as a member of the $B, B^{\prime}$, or $B^{\prime \prime}$ families [100]. The gene $P P P 2 R 3 C$ encodes the $\mathrm{B}^{\prime \prime}$ gamma subunit of PP2A [101, 102]. A single report has been published describing biallelic variants in $P P P 2 R 3 C$ with a syndromic form of 46,XY DSD [103]. Four affected girls from unrelated families presented with 46,XY complete GD, a typical facial dysmorphia, low birth weight, myopathy, rod and cone dystrophy, anal atresia, omphalocele, sensorineural hearing loss, dry and scaly skin, skeletal abnor- 
malities, renal agenesis, and neuromotor delay. Each girl carried biallelic variants in the PPP2R3C gene, establishing this as a new recessive form of syndromic 46,XY GD [103]. Many of the syndromic features are consistent with impaired chondrogenesis, and consistent with this, hypothesis data suggest that these variants may alter the phosphorylation of SOX9 which is required for both testis determination and chondrogenesis. Phosphorylation of SOX9 results in enhanced DNA-binding activity and translocation of the protein to the nucleus [104]. Male and female heterozygous carriers of these variants exhibit various degrees of infertility [103]. Carrier men have teratozoospermia, whilst some carrier females were reported to have oligomenorrhea or premature menopause [103].

\section{SOX Gene Family Variants and DSD: SRY, SOX8, and SOX9}

Fifteen percentage of 46,XY CGD patients carry variants involving the Y-linked testis-determining gene SRY. The majority of pathogenic variants are hemizygous missense variants clustered within the DNA-binding HMG domain [105], although rare deletions upstream and downstream of the gene as well as variants in the minimal promoter region have been reported [105-108]. Pathogenic variants in the $\mathrm{SOX} 9$ gene are associated with Campomelic dysplasia (CD), and testicular dysgenesis of variable degree is observed in $75 \%$ of affected XY individuals [109]. In rare occasions, patients with pathogenic variants may present with gonadal anomalies but not CD. Missense variants have been reported in undervirilized men with unpalpable testis and either hypospadias or micropenis [110]. In recent years, there has been renewed interest in $S O X 9$, with data indicating that rearrangements involving the SOX9 locus are relatively common causes of both nonsyndromic 46,XY and 46,XX DSD. These structural changes, involving multiple regions both upstream and downstream of SOX9, may disrupt the appropriate developmental timing of SOX9 expression. The structural changes include duplications, deletions, translocations, and inversions and explain about $10 \%$ of all patients with either 46,XY GD or SRY-negative 46,XX (ovo)testicular DSD. A comparison of common overlapping rearrangements in human DSD individuals has defined the key regulatory elements required for the control of SOX 9 expression in the developing gonad. The first regulatory element to be defined was termed TESCO [111]. This 1.4-kb region is located $13 \mathrm{~kb}$ upstream of Sox 9 and can positively regulate Sox 9 expression by binding of key sex-determining factors including NR5A1, SRY, and SOX9 it- self, and it can repress Sox9 expression through the binding of Foxl2 [111]. However, deletion of the Tesco enhancer in mice does not cause male-to-female sex reversal, and rearrangements of human TESCO have not been reported in DSD [112]. The analysis of individuals with either XY or XX DSD has identified other key regulatory elements of SOX9. Located approximately $600 \mathrm{~kb}$ upstream from SOX9, the RevSex element is duplicated in 46,XX (ovo)testicular DSD and deleted in individuals with 46,XY GD [113-116]. The minimal region associated with 46,XX-SRY-negative DSD has been narrowed down to a 40.7- to 41.9-kb element, which contains two predicted enhancer motifs [116]. Further analysis of 46,XX DSD individuals has narrowed the RevSex region to a $24-\mathrm{kb}$ minimal region that contains a core enhancer motif termed eSR-B [117]. An immediately adjacent and nonoverlapping second region that when deleted is associated with 46,XY GD is termed XYSR [118]. Further analysis of patients has refined XYSR to a minimum critical region of $5.2 \mathrm{~kb}$ [119]. Within this region, a core enhancer element, termed eSR-A, has been identified. Deletion of the minimum region including eSR-A causes XY $\mathrm{GD}$, whereas duplications of this region cause XX DSD [119]. A bioinformatic screen of human sequences upstream of the SOX9 locus identified a third potential enhancer element of 1,259 bp located immediately upstream of TESCO, termed eALDI that may regulate $S O X 9$ expression although to date no patients have been identified with rearrangements or other variants involving the aALDI enhancer [119].

Recent data from murine studies indicate another Sox family gene member, Sox8, is involved together with Sox 9 and other transcription factors in testis development as well as in the maintenance of Sertoli cell identity [120122]. SOX8 is co-expressed with NR5A1 and SOX9 in the early stages of human testis determination in Sertoli cells and Leydig cells as well as in Sertoli and Leydig cells in adult men [123]. SOX8 variants associated with 46,XY DSD are rare. Three individuals with 46,XY DSD and rearrangements at the SOX8 locus have been described $[123,124]$. A pericentric inversion and a complex rearrangement of SOX8 are associated with 46,XY nonsyndromic and syndromic GD, respectively [123]. A further case of 46,XY GD, skeletal and cardiac anomalies, and developmental delay had a $560-\mathrm{kb}$ duplication located approximately $18 \mathrm{~kb}$ upstream of SOX8 [124]. Variants in the SOX8 coding sequences, all located in regions flanking the HMG-box, are associated with both male and female infertility. A single case of $46, \mathrm{XY}$ GD has been described with a pathogenic missense variant located within
14

Horm Res Paediatr DOI: $10.1159 / 00052138$
McElreavey/Bashamboo 
the HMG-box [123]. This mutant protein displays dominant negative activity over the wild-type SOX8 and SOX9 proteins. This may explain the severity of the phenotype compared with other SOX8 variants causing infertility. However, we cannot rule out the possibility of genetic redundancy between SOX8 and SOX9 function. Thus, it is likely that pathogenic missense variants in SOX8 will be rare [32].

\section{ZNRF3}

In mammalian testis determination, Sry initiates a positive feedback loop between Sox9 and Fgf9, which results in upregulation of Fgf9 and repression of the ovarian factor Wnt4 [125]. Canonical WNT/ $\beta$-catenin signals are required for normal ovarian development, and variants in either WNT4 or Rspondin-1 (RSPO1), which are required for the stabilization of $\beta$-catenin, can result in syndromic forms of 46,XX DSD or virilization in 46,XX individuals [125-128]. The transmembrane E3 ubiquitin ligase ZNRF3 functions to inhibit WNT signaling by targeting the frizzled receptor for degradation by ubiquitination and increased membrane turnover. R-spondins function to promote WNT signaling by binding to and sequestering the negative regular ZNRF3 [129, 130]. In exome sequencing studies of the 46,XY DSD cohort, we identified two novel ZNRF3 variants and two known variants in five individuals [131]. No other DSD-associated variants were present in these patients. Two 46,XY females with GD carried novel ZNRF3 variants (c.2767+5G >A and p.Ser554Asn), two sisters with a milder phenotype of 46,XY DSD carried a rare missense variant (p.Arg768Gly), and a boy with perineal hypospadias, intrascrotal testis carried a different, rare missense variant (p.Arg621Ser). The genomic data were suggestive for a role of ZNRF3 in the pathogenesis of 46,XY DSD, but they were not conclusive. However, using in vitro cellular assays and zebrafish model, we demonstrated that the two missense variants (p.Ser554Asn and p.Arg768Gly) disrupted the ability of ZNRF3 to inhibit canonical WNT signals compared to wild-type ZNRF3. Mice carrying only one copy of the Znrf3 gene on the B6. $\mathrm{Y}^{\mathrm{AKR}}$ background showed widely different degrees of sex reversal consistent with the human DSD phenotypes. Together, these data indicate that ZNRF3 variants may contribute to a wide spectrum of DSD phenotypes. Since there has been only a single published study, the prevalence of ZNRF3 variants causing DSD remains to be established [32].

\section{Monogenetic Associations with 46,XY DSD Requiring Further Genetic or Experimental Evidence}

\section{ESR2}

Estrogens control development and cell differentiation by binding and activating their nuclear receptors, estrogen receptor a (ESR1) and $\beta$ (ESR2). Mice lacking Esr2 exhibit both male and female infertility with no evidence of DSD [132-134]. Consistent with these observation, a heterozygous missense variant (p.K314R) in ERS2 was identified in a 46,XX 16.5-year-old-girl who presented with primary amenorrhea [135]. Clinical evaluation revealed streak gonads, absent puberty, no breast development, infantile uterus, and osteoporosis. This variant is absent from public databases, and it is predicted to impair the interaction of ESR2 with nuclear coactivator 1 (NCoA1). Functional studies showed that the variant significantly impaired ESR2 signaling and exhibited dominant negative activity over the wild type [135]. A second case describing an ESR2 missense variant in association with 46,XX primary amenorrhea has been described although it is unclear if the phenotype was due to ovarian dysgenesis [136]. The combination of animal models, functional studies, and the location of the protein change suggests that pathogenic variants in ESR2 are a cause of ovarian dysgenesis, with the caveat that only a single patient has been described to date (Table 2).

The evidence to support a role for ESR2 variants contributing to 46,XY DSD is inconclusive. Monoallelic and biallelic variants in ESR2 have been reported in patients with syndromic and nonsyndromic 46,XY DSD [137]. The phenotypes of these individuals are varied. One case presented with a complex developmental phenotype including absence of uterus, fallopian tubes, gonads, and vagina, anal atresia, rectovestibular fistula, and ocular anomalies as well as facial dymorphism. A heterozygous 3-bp deletion resulting in the loss of a single amino acid p.Asn181del within the DNA-binding domain was found by exome sequencing. This variant has an allelic frequency of 3:2,000 46,XY men of South Asian origin (https:// gnomad.broadinstitute.org/variant/14-64735621CATT-C?dataset=gnomad_r2_1). Although rare, this allelic frequency in healthy $46, \mathrm{XY}$ men excludes this variant as the cause of the phenotype. The second case was an XY female with clitoromegaly, urogenital sinus, and absent uterus. Since FSH and $\mathrm{LH}$ levels were within normal range rather than elevated, it suggests that the individual may have had androgen insensitivity. Information on the gonads or gonadal hormones was unavailable. This girl carried a rare heterozygous missense variant p.G84V. No 
somatic anomalies were observed. The third case diagnosed with 46,XY complete GD carried a rare heterozygous p.L426R missense variant. Establishing an association between these ESR2 variants with 46,XY DSD is challenging since each of the clinical phenotypes is distinct, the functional analysis of the mutant proteins did not show a statistically significant change compared to the activity of the wild-type protein, and ESR2 expression could not be detected in the gonad of an 8-week-old male human embryo [137]. Therefore, the association of ESR2 variants with $46, \mathrm{XY}$ DSD remains to be established.

\section{FGFR2}

FGFR2 plays an essential role in osteoblast differentiation and proliferation and is required for normal skeleton development, embryonic patterning, trophoblast function, lung morphogenesis, and skin development [138]. In XY mice, the signaling pathway involving Fgf9 and its receptor Fgfr2 is required to repress pro-ovary Wnt 4 signaling in order to promote testis development [139]. Mice lacking Fgfr2 in the early developing XY gonad show a failure of testis determination [139]. Although this establishes that FGFR2 is involved in testis formation in mice, there is a lack of convincing evidence to indicate that FGFR2 variants in the human cause $46, \mathrm{XY}$ DSD. A single 46,XY individual with GD and craniosynostosis has been reported to carry a heterozygous p.Cys342Ser variant [140]. However, heterozygous pathogenic variants in the FGFR2 gene are associated with a range of phenotypes including Crouzon syndrome, Pfeiffer syndrome, and Apert syndrome, which share a common feature craniosynostosis [141-144]. DSD has not been reported in affected 46,XY individuals with these syndromes. The amino acid substitution, p.Cys342Ser, was previously reported to cause Crouzon or Pfeiffer syndromes and was carried by 46,XY males with no evidence for DSD $[141,144]$. This suggests that the GD seen in the patient carrying the FGFR2 variant is caused by an independent pathogenic variant involving a DSD gene elsewhere in the genome.

\section{HMGCS2}

Variants in the gene 3-hydroxy-3-methylglutaryl coenzyme A synthase 2 (HMGCS2), encoding a metabolic enzyme in the liver important for energy production from fatty acids, have been proposed to cause human DSD [145]. The expression of Himgcs2 in the developing gonad of the mouse is consistent with a role in early testis and ovary development, but mice that lack Hmgcs2 have normally developed gonads even on a sensitized genetic background [145]. In a screen of 46,XY DSD patients with GD, 2 patients were identified with a heterozygous deletion and a predicted deleterious heterozygous missense variant (p.Arg501Pro) in HMGCS2, respectively [145]. However, autosomal recessive variants, including LOF variants, in HMGCS2 are a well-established cause of HMG-CoA synthase-2 deficiency [146] with no evidence of DSD. Heterozygous carriers are healthy. Data from the gnom AD database indicate that HMCS2 is not a conserved gene in human populations $(\mathrm{pLI}=0)$ unlike other genes known to be involved in testis determination, which are intolerant to variation (e.g., DMRT1, SOX9, and NR5A1). These data do not provide compelling evidence in favor of causality of HMGCS2 variants in human DSD.

\section{LHX9}

LHX9 is a member of the LIM homeobox gene family that contains a homeodomain and 2 cysteine-rich LIM ZF domains. Variants in the LHX9 gene are excellent candidates to cause DSD, since both XY and XX mice lacking Lhx 9 are female and do not have gonads [147]. A single de novo and novel missense variant $\mathrm{p} . \mathrm{Q} 316 \mathrm{R}$ located within the DNA-binding homeodomain of the protein was reported in a 46,XY girl who presented with normal facial features, bilateral distal thumb hypoplasia with small nails and mild hypoplasia on the fifth fingernails bilaterally, absent left great toe, and hypoplastic right great toe with absent distal phalanx [148]. Although functional studies were performed, this is a good candidate variant for $46, \mathrm{XY}$ DSD as it impacts a highly conserved amino acid residue in a well-characterized functional domain, and it is predicted to disrupt the biological function. One or more other independent cases of DSD with variants in LHX9 would establish this as a rare cause of $46, \mathrm{XY}$ DSD.

\section{STARD8}

Rho-GTPases are important molecular switches that control a wide variety of signal transduction pathways in all eukaryotic cells. STARD8 is a Rho-GAPase that maps to chromosome Xq13. The protein consists of a sterile alpha motif (SAM), GAP, and START (steroidogenic acute regulatory protein $[\mathrm{StAR}]$-related lipid transfer) domain [149, 150]. A missense variant in STARD8 has been proposed to cause 46,XY GD in a familial case of DSD [151]. Two sisters with 46,XY GD were found to carry a hemizygous missense variant (p.Ser993Asn; rs201005000, also termed p.Ser913Asn in a shorter isoform), inherited from their heterozygous mother. Gonadal tissue of one of the sisters contained Leydig cells overloaded with cholesterol droplets, i.e., structures previously identified in $46, \mathrm{XY}$ DSD patients
16

Horm Res Paediatr DOI: $10.1159 / 00052138$
McElreavey/Bashamboo 
carrying variants in the STAR gene encoding a related START domain family member. The p.Ser993Asn variant, which in silico predictions indicate as benign, is present in Bulgarian populations with a relatively high allelic frequency (1/500 alleles). Although STARD8 is a promising candidate, the evidence for a role of pathogenic variants in STARD8 causing DSD remains inconclusive.

\section{WWOX}

The human $W W O X$ gene, located at a common fragile site FRA16D on chromosome 16q23.3-24.1, encodes a tumor suppressor WW domain-containing oxidoreductase, WWOX [152]. The relationship between variants in the WWOX gene with DSD was first proposed by the identification of a boy with $46, \mathrm{XY}$ DSD who carried a maternally inherited deletion removing exons 6-8 of the WWOX gene [153]. Although WWOX continues to be used in targeted panel and exome analysis of DSD individuals [30-32], there is now a large body of work to indicate that variants in WWOX are not associated with DSD. Homozygous or compound heterozygous variants are associated with autosomal recessive spinocerebellar ataxia-12 (SCAR12) [154] and early infantile epileptic encephalopathy-28 (EIEE28; also known as WOREE syndrome) [155]. These data are supported by animal models $[154,156]$. Other families have been published with biallelic variants causing these syndromic phenotypes [157160]. In these families, there is no evidence of DSD in either affected individuals or carriers of deleterious variants. Variants in WWOX should therefore not be considered a cause of human DSD.

\section{Monogenic Causes of 46,XX DSD}

The most common form of 46,XX DSD is congenital adrenal hypoplasia. Excellent overviews of monogenic causes of adrenal insufficiency have been recently published [161, 162]. World-wide 21-hydroxylase deficiency (21-OHD, CYP21A2) is the most common cause of autosomal recessive $\mathrm{CAH}$ with a variable incidence of 1:10,000-1:20,000 depending on the degree of consanguinity within the population [161]. Other rare autosomal recessive forms of $\mathrm{CAH}$ include 11 beta-hydroxylase deficiency (CYP11B1), 3 beta-hydroxysteroid dehydrogenase deficiency (HSD3B2), and 17 alpha-hydroxylase deficiency (CYP17A1) and P450 oxidoreductase deficiency caused by biallelic variants in the gene POR [161].

$46, X X$ DSD due to errors in sex-determination, i.e., the formation of testis tissue in a $46, \mathrm{XX}$ gonad, presents as either ovotesticular or testicular DSD. These phenotypes are usually caused by the presence of the testis-determining gene $S R Y$ on one of the $\mathrm{X}$ chromosomes. Very rare cases are due to variants in the WNT signaling pathway. Only 4 families have been identified with a recessive form of syndromic 46,XX testicular/ovotesticular DSD due to variants in the RSPO1 gene ([163] and references therein). Variants in WNT4 associated with 46,XX DSD are even rarer. Heterozygous LOF variants involving WNT4 have been described in three 46,XX patients with mild virilization but with an apparent lack of testis tissue [164]. A single family has been described with a homozygous missense variant in WNT4 associated with a complex syndrome of renal agenesis, adrenal hypoplasia, and pulmonary and cardiac abnormalities. Testicular tissue was present in the affected 46,XX individuals who exhibited various degrees of virilization [164]. Here, we will discuss some of the more recent and surprising causes of 46,XX DSD that have been identified through exome sequencing (Table 3).

\section{WT1}

The mammalian Wilms' tumor 1 (WT1) gene encodes for a transcription factor with over 30 potential isoforms that are generated by a number of mechanisms including alternative transcription start sites, alternative translation start sites, splicing, and RNA editing. WT1 has a complex biology and as a result has a role in a myriad of developmental processes including but not limited to homeostasis and disease of tissues arising from the intermediate and lateral plate mesoderm, mesenchymal epithelial plasticity, and fundamental aspects of transcription and epigenetic regulation ([165] and references therein). Point mutations in WT1 are a well-established cause of two rare forms of 46,XY DSD: Frasier syndrome (a splice site variant) and Denys-Drash syndrome (DDS; variants in exon 8 or 9). 46,XY individuals with DDS have ambiguous or female external genitalia with normal or undescended testes or GD with mesangial sclerosis of the glomerulus and may develop Wilms' tumor [166]. Frasier syndrome is characterized by focal nodular glomerulosclerosis and 46,XY DSD with streak gonads and feminized to female external genitalia [167]. Another less-frequent syndrome, and one that overlaps with DDS, is Meacham syndrome, which is characterized by $\mathrm{CDH}$, ambiguous genitalia, and complex congenital heart defects but no renal abnormalities in 46,XY individuals [168]. Until recently, variants in the WT1 gene were considered to have a mild effect on ovarian development. Fifteen WT1 variants have been reported in 46,XX girls that are associated with either ap- 
parently normal functioning ovaries, premature ovarian failure, or streak ovaries [169, 170].

Recently, in a series of 78 children presenting with $S R Y$-negative 46,XX OTDSD/TDSD, we identified 7 families with recurrent missense and frameshift variants impacting the 4th ZF of WT1 [14]. This is one of the most common causes of $S R Y$-negative 46,XX (ovo)testicular DSD. In vitro transient transactivation assays demonstrated that the WT1 protein with mutated 4th ZF shows aberrant biological activity compared to the wild-type protein. Remarkably, when introduced into a human granulosa cell line, the variant results in the upregulation of endogenous Sertoli-specific transcripts. Mutating the 4th ZF of Wt1 results in masculinization of the gonad in $\mathrm{XX}$ mice [14]. These variants may induce testis formation through the ability of the mutated, but not the wild-type protein, to physically interact with the key pro-ovarian and anti-testis factor $\beta$-catenin. This inappropriate interaction is predicted to result in the direct or indirect inactivation of pro-testis signaling pathway(s). OTDSD/ TDSD has been reported to be associated with WT1 ZF4 variants in other studies [171, 172]. The question of whether variants in WT1, which cause 46,XX DSD, are also associated with somatic anomalies as well as an increased tumor risk is unclear. Of the 7 original cases of $46, X X$ DSD, none were reported to have renal disease nor tumor development although one individual had a diaphragmatic hernia [14]. However, 6 of the 7 affected individuals were young children, and they will require longterm monitoring. The 46,XX DSD girl with atypical genitalia reported by Gomes and colleagues $[171,172]$ was diagnosed with proteinuria at 14 years of age indicating that there is a risk of renal disease developing within this subgroup of 46,XX DSD.

\section{NR2F2}

The chicken ovalbumin upstream promoter-transcription factor type II (COUP-TFII also termed NR2F2) is a member of the steroid/thyroid nuclear receptor superfamily and is structurally related to the orphan nuclear receptor NR5A1 [173]. Globally, murine Coup-tf2 is highly abundant at E14-E15 in the mesenchymal compartment of the developing organs and declines after the completion of organogenesis [173]. The absence of NR2F2 in the terminally differentiated epithelium suggests that NR2F2 plays a major role in the mesenchymalepithelial transition. In mice, Coup-Tf2 is involved in the development of multiple organs and tissues by modulating the expression of downstream targets to promote cellular differentiation, proliferation, migration, survival, and intercellular communication [173, 174]. Homozygous Nr2f2 null mice die at embryonic day 10 due to its requirement for angiogenesis and heart development [175]. Nr2f2 also plays essential roles in cell differentiation and organogenesis of the stomach, uterus, diaphragm, limbs, and skeletal muscle. There is emerging evidence over the last few years for an important role for NR2F2 in Leydig cell formation. In XY male mice, $\mathrm{NR} 2 \mathrm{~F} 2$ is essential for the differentiation and function of fetal and adult Leydig cells [176-178]. Inactivation of $\mathrm{Nr} 2 f 2$ during prepubertal stages of male sexual development results in infertility, hypogonadism, and a block in spermatogenesis due to a failure of progenitor Leydig


a wide range of reproductive anomalies including reduced fecundity, irregular estrus cycles, delayed puberty, retarded postnatal growth, and reduced levels of steroidogenic enzymes, but virilization and testis development has not been reported [179]. XX mice lacking $N r 2 f 2$ have both Müllerian and Wolffian ducts in the mesonephros [180]. The ovaries of these mice do not produce androgens, but an androgen-independent activation of the p-ERK pathway in the Wolffian duct epithelium was observed that leads to the presence of Wolffian duct tissue [180].

In the human, heterozygous, and usually de novo, variants have been reported in NR2F2 associated with $\mathrm{CHD}$ and/or CDH [181-183]. In a screen of 79 individuals with 46,XX SRY-negative testicular or ovotesticular DSD, we identified three children with near-identical heterozygous frameshift variants in at the $\mathrm{N}$-terminal of NR2F2 [8]. These are predicted to be complete LOF because the frameshift variants are located at the N-terminal region of the protein. In two of three children, the variant was de novo. All three children presented with remarkably similar phenotypes. Each child presented with $\mathrm{CHD}$, one child with $\mathrm{CDH}$, and two children with blepharophimosis-ptosis-epicanthus inversus syndrome. The role of NR2F2 in human ovarian development is unknown. Functional studies on the mutant protein were not performed as the protein-truncating variant occurs at the $\mathrm{N}$-terminus of the protein, and the truncated protein does not contain any known functional domains. The contribution (if any) of NR2F2 variants to $46, \mathrm{XY}$ DSD remains to be established.

\section{NR5A1}

NR5A1, also known as steroidogenic factor-1 (SF-1), is an orphan nuclear receptor transcription factor that plays a key role in many aspects of reproductive develop-
18

Horm Res Paediatr

DOI: $10.1159 / 00052138$
McElreavey/Bashamboo 
ment and function [184]. In 46,XY individuals, the phenotypes associated with NR5A1 variants include a wide range of DSD conditions with or usually without adrenal insufficiency, including testicular dysgenesis with or without Müllerian structures, anomalies of androgen production, hypospadias, progressive androgenization at puberty, and male infertility with normal genital development [185]. In 46,XX individuals, pathogenic variants are associated with primary ovarian insufficiency and early menopause [185]. Recently, the range of phenotypes associated with the variant in NR5A1 has been extended to include 46,XX DSD. Amino acid variants of a specific arginine residue, p.Arg92, located in the highly conserved "A-box," which is required for appropriate DNA-binding, are associated with $46, \mathrm{XX}$ ovotesticular DSD or testicular DSD [16, 184-188]. To date, this phenotype has not been observed with missense variants elsewhere in the NR5A1 protein in 46,XX individuals. More than twenty 46,XX (ovo)testicular DSD cases with changes in the p.Arg92 residue have been reported establishing the causality of p.Arg92. The phenotype is highly variable, and the variant can be transmitted by a normal fertile mother. Changes in the Arg92 variant result in an absence of DNA binding by NR5A1 [16]. How this change in biological activity results in testis formation in 46,XX individuals is unclear although it has been proposed that the pathogenic variant may abolish the ability of NR5A1 to repress the pro-ovarian pathway of WNT $4 / \beta$-catenin $[16$, 188].

\section{Conclusions}

The widespread availability of exome and genomic sequencing is revolutionizing our understanding of the genetic causes of rare congenital disorders, including DSD. However, the generation of large genomic datasets also raises questions concerning the interpretation of the data. The first point to consider is the interpretation of variants in genes that are well established as a cause of DSD. Aside from in silico tools that can provide information on the effects of a variant on protein function, the interpretation of these variants can be aided by simply determining their allelic frequencies in publicly available population genetic datasets. Using population genetics data is a very powerful tool to exclude the possibility that a gene or a specific variant is responsible for DSD. There is a need to consider the wealth of human population genetics data that are now available for different populations worldwide, which often includes the karyotype of the individual carrying each variant. These data can be rapidly used to exclude either a gene or specific variants as causal (e.g., ESR2 and MAMLD1). Databases such as gnom $\mathrm{AD}$ also offer tools that determine if a variant is likely to be pathogenic based on observed population genetics data. Determining the ancestry of the DSD family therefore is essential for the interpretation of the population genomic datasets. In parallel with this, for genes that are established to cause DSD such as MAP3K1 and $M A M L D 1$, there is a need for simple, robust, and biologically relevant functional assays to determine variant pathogenicity. In the absence of functional data, the contribution of missense variants in genes such as MAP $3 K 1$ and MAMLD1 will continue to be classified as VUS. A good example of where functional studies can aid interpretation of pathogenicity is missense variants reported in GATA4, where variants located within the $\mathrm{N}$-terminal $\mathrm{ZF}$ are pathogenic and those outside are not pathogenic $[21,70-73]$. Variant interpretation will be improved if variants that are identified in routine diagnostic screening are made available publicly through databases such as ClinVar (https://www.ncbi.nlm.nih.gov/clinvar/), which reports the relationships between human variations and phenotypes, together with supporting evidence. As more DSD variants are added to such publicly available databases, not only will the accuracy in the interpretation of pathogenicity of such variants improve but also genotype-phenotype relationships may be established.

The second point to consider is a growing number of new genes which are reported to cause DSD. For some genes, their contribution to DSD is questionable. This can be due to either the absence of supporting evidence or that available data indicate that the gene is unlikely to cause DSD (e.g., population genetics data, gene known to cause other phenotypes but not DSD, and functional data show no difference from wild-type protein). For some new genes, such as LHX9, causality may be established if other independent DSD cases with potentially pathogenic variants are reported with supporting functional studies. Sufficient affected individuals with the same or similar phenotype carrying potentially pathogenic variants may allow a statistical comparison with appropriate ancestry-matched control groups.

\section{Conflict of Interest Statement}

The authors have no conflicts of interest to declare. 


\section{Funding Sources}

This work was funded in part by a research grant from the European Society of Pediatric Endocrinology and by the Agence Nationale de la Recherche (ANR), ANR-10-LABX-73 REVIVE, ANR-17-CE14-0038-01, ANR-19-CE14-0022, and ANR-19CE14-0012.

\section{References}

1 Hughes IA, Houk C, Ahmed SF, Lee PA; LWPES Consensus Group; ESPE Consensus Group. Consensus statement on management of intersex disorders. J Pediatr Urol. 2006;2: $148-62$.

2 Lee PA, Nordenström A, Houk CP, Ahmed SF, Auchus R, Baratz A, et al. Global disorders of sex development update since 2006: perceptions, approach and care. Horm Res Paediatr. 2016;85(3):158-80.

3 Ahmed SF, Achermann J, Alderson J, Crouch NS, Elford S, Hughes IA, et al. Society for Endocrinology UK Guidance on the initial evaluation of a suspected difference or disorder of sex development (revised 2021). Clin Endocrinol. 2021 Dec;95(6):818-40.

4 Bennecke E, Bernstein S, Lee P, van de Grift TC, Nordenskjöld A, Rapp M, et al. Early genital surgery in disorders/differences of sex development: patients' perspectives. Arch Sex Behav. 2021 Apr;50(3):913-23.

5 Bashamboo A, Eozenou C, Rojo S, McElreavey $\mathrm{K}$. Anomalies in human sex determination provide unique insights into the complex genetic interactions of early gonad development. Clin Genet. 2017;91:143-56.

6 Audi L, Ahmed SF, Krone N, Cools M, McElreavey $\mathrm{K}$, Holterhus PM, et al. Genetics in endocrinology: approaches to molecular genetic diagnosis in the management of differences/ disorders of sex development (DSD) - position paper of EU COST Action BM 1303 "DSDnet". Eur J Endocrinol. 2018;179:R197-206.

7 Miyado M, Inui M, Igarashi M, Katoh-Fukui Y, Takasawa K, Hakoda A, et al. The p.R92W variant of NR5A1/Nr5al induces testicular development of 46,XX gonads in humans, but not in mice: phenotypic comparison of human patients and mutation-induced mice. Biol Sex Differ. 2016 Nov 8; 7:56.

8 Bashamboo A, Eozenou C, Jorgensen A, Bignon-Topalovic J, Siffroi JP, Hyon C, et al. Loss of function of the nuclear receptor NR2F2, rncoding COUP-TF2, causes testis development and cardiac defects in 46,XX children. Am J Hum Genet. 2018 Mar 1;102(3):487-93.

9 Kalfa N, Gaspari L, Ollivier M, Philibert P, Bergougnoux A, Paris F, et al. Molecular genetics of hypospadias and cryptorchidism recent developments. Clin Genet. 2019;95:12231.

10 Baskin LS. New insights into hypospadias: next-generation sequencing reveals potential genetic factors in male urethral development. Eur Urol. 2021 Apr;79(4):516-8.

\section{Author Contributions}

Both authors wrote the manuscript.
11 Ea V, Bergougnoux A, Philibert P, ServantFauconnet N, Faure A, Breaud J, et al. How far should we explore hypospadias? Next-generation sequencing applied to a large cohort of hypospadiac patients. Eur Urol. 2021 Apr; 79(4):507-15.

12 da Silva TE, Gomes NL, Lerário AM, Keegan CE, Nishi MY, Carvalho FM, et al. Genetic evidence of the association of DEAH-box helicase 37 defects with 46,XY gonadal dysgenesis spectrum. J Clin Endocrinol Metab. 2019; 104:5923-34.

13 McElreavey K, Jorgensen A, Eozenou C, Merel T, Bignon-Topalovic J, Tan DS, et al. Pathogenic variants in the DEAH-box RNA helicase DHX37 are a frequent cause of $46, \mathrm{XY}$ gonadal dysgenesis and 46,XY testicular regression syndrome. Genet Med. 2020;22:1509.

14 Eozenou C, Gonen N, Touzon MS, Jorgensen A, Yatsenko SA, Fusee L, et al. Testis formation in XX individuals resulting from novel pathogenic variants in Wilms' tumor 1 (WT1) gene. Proc Natl Acad Sci U S A. 2020 Jun 16; 117(24):13680-8.

15 Knarston IM, Robevska G, van den Bergen JA, Eggers S, Croft B, Yates J, et al. NR5A1 gene variants repress the ovarian-specific WNT signaling pathway in 46,XX disorders of sex development patients. Hum Mutat. 2019 Feb;40(2):207-16.

16 Bashamboo A, Donohoue PA, Vilain E, Rojo $S$, Calvel P, Seneviratne SN, et al. A recurrent p.Arg92Trp variant in steroidogenic factor-1 (NR5A1) can act as a molecular switch in human sex development. Hum Mol Genet. 2016 Aug 15;25(16):3446-53.

17 Domenice S, Machado AZ, Ferreira FM, Ferraz-de-Souza B, Lerario AM, Lin L, et al. Wide spectrum of NR5A1-related phenotypes in 46,XY and 46,XX individuals. Birth Defects Res C Embryo Today. 2016 Dec;108(4):309-20.

18 Ochoa MF, Yankovic F, Poggi H, Martinez A. Different clinical manifestations related to subvirilization in three XY patients with the same pathogenic variant of steroidogenic factor 1. AACE Clin Case Rep. 2021 Mar;7(2): $145-8$.

19 Martínez de LaPiscina I, Mahmoud RA, Sauter KS, Esteva I, Alonso M, Costa I, et al. Variants of STAR, AMH and ZFPM2/FOG2 May contribute towards the broad phenotype observed in 46,XY DSD patients with heterozygous variants of NR5A1. Int J Mol Sci. 2020 Nov 13;21(22):8554.
20 Flück CE, Audí L, Fernández-Cancio M, Sauter KS, Martinez de LaPiscina I, Castaño L, et al. Broad phenotypes of disorders/differences of sex development in MAMLD1 patients through oligogenic disease. Front Genet. 2019 Aug 29;10:746.

21 Martinez de LaPiscina I, de Mingo C, Riedl S, Rodriguez A, Pandey AV, Fernández-Cancio $\mathrm{M}$, et al. GATA4 variants in individuals with a 46,XY Disorder of Sex Development (DSD) may or may not be associated with cardiac defects depending on second hits in other DSD genes. Front Endocrinol. 2018 Apr 4;9:142.

22 Josso N, Rey RA. What does AMH tell us in pediatric disorders of sex development? Front Endocrinol. 2020 Sep 8;11:619.

23 Mongan NP, Tadokoro-Cuccaro R, Bunch T, Hughes IA. Androgen insensitivity syndrome. Best Pract Res Clin Endocrinol Metab. 2015 Aug;29(4):569-80.

24 Baronio F, Ortolano R, Menabò S, Cassio A, Baldazzi L, Di Natale V, et al. 46,XX DSD due to androgen excess in monogenic disorders of steroidogenesis: genetic, biochemical, and clinical features. Int J Mol Sci. 2019;20:E4605.

25 Grinspon RP, Bergadá I, Rey RA. Male hypogonadism and disorders of sex development. Front Endocrinol. 2020 Apr 15;11:211.

26 Katoh-Fukui Y, Tsuchiya R, Shiroishi T, Nakahara Y, Hashimoto N, Noguchi K, et al. Male-to-female sex reversal in M33 mutant mice. Nature. 1998 Jun 18;393(6686):688-92.

27 Garcia-Moreno SA, Lin YT, Futtner CR, Salamone IM, Capel B, Maatouk DM. CBX2 is required to stabilize the testis pathway by repressing Wnt signaling. PLoS Genet. 2019;15: e1007895.

28 Biason-Lauber A, Konrad D, Meyer M, DeBeaufort C, Schoenle EJ. Ovaries and female phenotype in a girl with 46,XY karyotype and mutations in the CBX2 gene. Am J Hum Genet. 2009;84:658-63.

29 Norling A, Hirschberg AL, Iwarsson E, Wedell A, Barbaro M. CBX2 gene analysis in patients with 46,XY and 46,XX gonadal disorders of sex development. Fertil Steril. 2013;99: 819-26.e3.

30 Eggers S, Sadedin S, van den Bergen JA, Robevska G, Ohnesorg T, Hewitt J, et al. Disorders of sex development: insights from targeted gene sequencing of a large international patient cohort. Genome Biol. 2016 Nov 29; 17(1):243. 
31 Kim JH, Kang E, Heo SH, Kim GH, Jang JH, Cho EH, et al. Diagnostic yield of targeted gene panel sequencing to identify the genetic etiology of disorders of sex development. Mol Cell Endocrinol. 2017;444:19-25.

32 Buonocore F, Clifford-Mobley O, King TFJ, Striglioni N, Man E, Suntharalingham JP, et al. Next-generation sequencing reveals novel genetic variants (SRY, DMRT1, NR5A1, DHH, DHX37) in adults with 46,XY DSD. J Endocr Soc. 2019;3:2341-60.

33 Camats N, Fernández-Cancio $\mathrm{M}$, Audí L, Schaller A, Flück CE. Broad phenotypes in heterozygous NR5A1 46,XY patients with a disorder of sex development: an oligogenic origin? Eur J Hum Genet. 2018;26:1329-38.

34 Baxter RM, Arboleda VA, Lee H, Barseghyan H, Adam MP, Fechner PY, et al. Exome sequencing for the diagnosis of 46,XY disorders of sex development. J Clin Endocrinol Metab. 2015;100:E333-44.

35 Sproll P, Eid W, Gomes CR, Mendonca BB, Gomes NL, Costa EM, et al. Assembling the jigsaw puzzle: $\mathrm{CBX} 2$ isoform 2 and its targets in disorders/differences of sex development. Mol Genet Genomic Med. 2018;6:785-95.

36 Huang CC, Yao HH. Diverse functions of Hedgehog signaling in formation and physiology of steroidogenic organs. Mol Reprod Dev. 2010;77:489-96.

37 Tajouri A, Kharrat M, Hizem S, Zaghdoudi H, M'rad R, Simic-Schleicher G, et al. In vitro functional characterization of the novel $\mathrm{DHH}$ mutations p.(Asn337Lysfs*24) and p.(Glu212Lys) associated with gonadal dysgenesis. Hum Mutat. 2018:39:2097-109.

38 Ayers K, van den Bergen J, Robevska G, Listyasari N, Raza J, Atta I, et al. Functional analysis of novel desert hedgehog gene variants improves the clinical interpretation of genomic data and provides a more accurate diagnosis for patients with 46,XY differences of sex development. J Med Genet. 2019 Jul; 56(7):434-43.

39 Edman CD, Winters AJ, Porter JC, Wilson J, MacDonald PC. Embryonic testicular regression. A clinical spectrum of XY agonadal individuals. Obstet Gynecol. 1977;49:208-17.

40 Josso N, Briard ML. Embryonic testicular regression syndrome: variable phenotypic expression in siblings. J Pediatr. 1980;97:200-4.

41 Pirgon Ö, Dündar BN. Vanishing testes: a literature review. J Clin Res Pediatr Endocrinol. 2012;4:116-20.

42 Marcantonio SM, Fechner PY, Migeon CJ, Perlman EJ, Berkovitz GD. Embryonic testicular regression sequence: a part of the clinical spectrum of 46,XY gonadal dysgenesis. Am J Med Genet. 1994;49:1-5.

43 Fechner PY, Marcantonio SM, Ogata T, Rosales TO, Smith KD, Goodfellow PN, et al. Report of a kindred with X-linked (or autosomal dominant sex-limited) 46,XY partial gonadal dysgenesis. J Clin Endocrinol Metab. 1993;76: 1248-53.
44 Phipps KR, Charette J, Baserga SJ. The small subunit processome in ribosome biogenesis: progress and prospects. Wiley Interdiscip Rev RNA. 2011;2:1-21.

45 Zhu J, Liu X, Anjos M, Correll CC, Johnson AW. Utp14 recruits and activates the RNA helicase Dhr1 to undock U3 snoRNA from the preribosome. Mol Cell Biol. 2016;36:965-78.

46 Black JJ, Wang Z, Goering LM, Johnson AW. Utp14 interaction with the small subunit processome. RNA. 2018;24:1214-28.

47 Bohnsack KE, Ficner R, Bohnsack MT, Jonas S. Regulation of DEAH-box RNA helicases by G-patch proteins. Biol Chem. 2021 Jan 6; 402(5):561-79.

48 Baßler J, Hurt E. Eukaryotic ribosome assembly. Annu Rev Biochem. 2019 Jun 20;88:281306.

49 Jankowsky E, Fairman ME. RNA helicases: one fold for many functions. Curr Opin Struct Biol. 2007 Jun; 17(3):316-24.

50 Sloan KE, Bohnsack MT. Unravelling the mechanisms of RNA helicase regulation. Trends Biochem Sci. 2018 Apr;43(4):237-50.

51 Choudhury P, Hackert P, Memet I, Sloan KE, Bohnsack MT. The human RNA helicase DHX37 is required for release of the U3 snoRNP from pre-ribosomal particles. RNA Biol. 2019 Jan;16(1):54-68.

52 Zidoune H, Martinerie L, Tan DS, Askari M, Rezgoune D, Ladjouze A, et al. Expanding DSD phenotypes associated with variants in the DEAH-box RNA helicase DHX37. Sex Dev. 2021;15(4):244-52.

53 Karaca E, Harel T, Pehlivan D, Jhangiani SN, Gambin T, Coban Akdemir Z, et al. Genes that affect brain structure and function identified by rare variant analyses of Mendelian neurologic disease. Neuron. 2015 Nov 4; 88(3):499-513.

54 Paine I, Posey JE, Grochowski CM, Jhangiani SN, Rosenheck S, Kleyner R, et al. Paralog studies augment gene discovery: DDX and DHX genes. Am J Hum Genet. 2019 Aug 1; 105(2):302-16.

55 Kampen KR, Sulima SO, Vereecke S, De Keersmaecker K. Hallmarks of ribosomopathies. Nucleic Acids Res. 2020 Feb 20;48(3): 1013-28.

56 Norris K, Hopes T, Aspden JL. Ribosome heterogeneity and specialization in development. Wiley Interdiscip Rev RNA. 2021 Jul;12(4): e1644.

57 Venturi G, Montanaro L. How altered ribosome production can cause or contribute to human disease: the spectrum of ribosomopathies. Cells. 2020 Oct 15;9(10):2300.

58 Hirata $\mathrm{H}$, Ogino K, Yamada K, Leacock S, Harvey RJ. Defective escape behavior in DEAH-box RNA helicase mutants improved by restoring glycine receptor expression. J Neurosci. 2013 Sep 11;33(37):14638-44.

59 Dong MB, Wang G, Chow RD, Ye L, Zhu L, Dai X, et al. Systematic immunotherapy target discovery using genome-scale in vivo CRISPR screens in CD8 T cells. Cell. 2019 Aug 22; 178(5):1189-204.e23.
60 Sulima SO, Hofman IJF, De Keersmaecker K, Dinman JD. How ribosomes translate cancer. Cancer Discov. 2017;7:1069-87.

61 Zarkower D, Murphy MW. DMRT1: an ancient sexual regulator required for human gonadogenesis. Sex Dev. 2021:1-87. Epub ahead of print.

62 Matson CK, Murphy MW, Sarver AL, Griswold MD, Bardwell VJ, Zarkower D. DMRT1 prevents female reprogramming in the postnatal mammalian testis. Nature. 2011;476: 101-4.

63 Ottolenghi C, McElreavey K. Deletions of 9p and the quest for a conserved mechanism of sex determination. Mol Genet Metab. 2000 Sep-Oct;71(1-2):397-404.

64 Murphy MW, Lee JK, Rojo S, Gearhart MD, Kurahashi K, Banerjee S, et al. An ancient protein-DNA interaction underlying metazoan sex determination. Nat Struct Mol Biol. 2015 Jun;22(6):442-51.

65 Robert NM, Miyamoto Y, Taniguchi H, Viger RS. LRH-1/NR5A2 cooperates with GATA factors to regulate inhibin alpha-subunit promoter activity. Mol Cell Endocrinol. 2006 Sep 26;257, 258:65-74.

66 Manuylov NL, Zhou B, Ma Q, Fox SC, Pu WT, Tevosian SG. Conditional ablation of Gata4 and Fog2 genes in mice reveals their distinct roles in mammalian sexual differentiation. Dev Biol. 2011 May 15;353(2):229-41.

67 Crispino JD, Lodish MB, Thurberg BL, Litovsky SH, Collins T, Molkentin JD, et al. Proper coronary vascular development and heart morphogenesis depend on interaction of GATA-4 with FOG cofactors. Genes Dev. 2001;15:839-44.

68 Bouma GJ, Washburn LL, Albrecht KH, Eicher EM. Correct dosage of Fog2 and Gata4 transcription factors is critical for fetal testis development in mice. Proc Natl Acad Sci U S A. 2007;104:14994-9.

69 Wat MJ, Shchelochkov OA, Holder AM, Breman AM, Dagli A, Bacino C, et al. Chromosome $8 \mathrm{p} 23.1$ deletions as a cause of complex congenital heart defects and diaphragmatic hernia. Am J Med Genet A. 2009;149A:166177.

70 Lourenço D, Brauner R, Rybczynska M, Nihoul-Fékété C, McElreavey K, Bashamboo A. Loss-of-function mutation in GATA4 causes anomalies of human testicular development. Proc Natl Acad Sci U S A. 2011 Jan 25;108(4): 1597-602.

71 Choi JH, Lee Y, Oh A, Kim GH, Yoo HW Molecular characteristics of sequence variants in GATA4 in patients with 46,XY disorders of sex development without cardiac defects. Sex Dev. 2019;13(5-6):240-5.

72 van den Bergen JA, Robevska G, Eggers S, Riedl S, Grover SR, Bergman PB, et al. Analysis of variants in GATA4 and FOG2/ZFPM2 demonstrates benign contribution to $46, \mathrm{XY}$ disorders of sex development. Mol Genet Genomic Med. 2020 Mar;8(3):e1095. 
73 Igarashi M, Mizuno K, Kon M, Narumi S, Kojima Y, Hayashi Y, et al. GATA4 mutations are uncommon in patients with $46, \mathrm{XY}$ disorders of sex development without heart anomaly. Asian J Androl. 2018 Nov-Dec;20(6): 629-31.

74 Zaytouni T, Efimenko EE, Tevosian SG. GATA transcription factors in the developing reproductive system. Adv Genet. 2011;76:93-134.

75 Tevosian SG, Albrecht KH, Crispino JD, Fujiwara Y, Eicher EM, Orkin SH. Gonadal differentiation, sex determination and normal Sry expression in mice require direct interaction between transcription partners GATA4 and FOG2. Development. 2002 Oct;129(19): 4627-34.

76 Bashamboo A, Brauner R, Bignon-Topalovic J, Lortat-Jacob S, Karageorgou V, Lourenco $\mathrm{D}$, et al. Mutations in the FOG2/ZFPM2 gene are associated with anomalies of human testis determination. Hum Mol Genet. 2014 Jul 15; 23(14):3657-65.

77 Matevossian A, Resh MD. Membrane topology of hedgehog acyltransferase. J Biol Chem. 2015;290:2235-43.

78 Callier P, Calvel P, Matevossian A, Makrythanasis $\mathrm{P}$, Bernard P, Kurosaka H, et al. Loss of function mutation in the palmitoyl-transferase HHAT leads to syndromic 46,XY disorder of sex development by impeding Hedgehog protein palmitoylation and signaling. PLoS Genet. 2014;10:e1004340.

79 Abdel-Salam GMH, Mazen I, Eid M, Ewida $\mathrm{N}$, Shaheen R, Alkuraya FS. Biallelic novel missense HHAT variant causes syndromic microcephaly and cerebellar-vermis hypoplasia. Am J Med Genet A. 2019 Jun;179(6): 1053-7.

80 Mazen I, Mekkawy M, Kamel A, Essawi M, Hassan H, Abdel-Hamid M, et al. Advances in genomic diagnosis of a large cohort of Egyptian patients with disorders of sex development. Am J Med Genet A. 2021 Jun;185(6): 1666-77.

81 Fukami M, Wada Y, Okada M, Kato F, Katsumata N, Baba T, et al. Mastermind-like domain-containing 1 (MAMLD1 or CXorf6) transactivates the Hes3 promoter, augments testosterone production, and contains the SF1 target sequence. J Biol Chem. 2008 Feb 29; 283(9):5525-32.

82 Fukami M, Wada Y, Miyabayashi K, Nishino I, Hasegawa T, Nordenskjöld A, et al. CXorf6 is a causative gene for hypospadias. Nat Genet. 2006 Dec;38(12):1369-71.

83 Ruiz-Arana IL, Hübner A, Cetingdag C, Krude H, Grüters A, Fukami M, et al. A novel hemizygous mutation of MAMLD1 in a patient with $46, \mathrm{XY}$ complete gonadal dysgenesis. Sex Dev. 2015;9(2):80-5.

84 Brandão MP, Costa EM, Fukami M, Gerdulo M, Pereira NP, Domenice S, et al. MAMLD1 (mastermind-like domain containing 1) homozygous gain-of-function missense mutation causing 46,XX disorder of sex development in a virilized female. Adv Exp Med Biol. 2011;707:129-31.
85 Miyado M, Yoshida K, Miyado K, Katsumi M, Saito K, Nakamura S, et al. Knockout of murine Mamld1 impairs testicular growth and daily sperm production but permits normal postnatal androgen production and fertility. Int J Mol Sci. 2017 Jun 19;18(6):1300.

86 Li L, Su C, Fan L, Gao F, Liang X, Gong C. Clinical and molecular spectrum of 46,XY disorders of sex development that harbour MAMLD1 variations: case series and review of literature. Orphanet J Rare Dis. 2020 Jul 20; 15(1): 188

87 Camats N, Fernández-Cancio $\mathrm{M}$, Audí L, Mullis PE, Moreno F, González Casado I, et al. Human MAMLD1 gene variations seem not sufficient to explain a 46,XY DSD phenotype. PLoS One. 2015 Nov 16;10(11): e0142831.

88 Pearlman A, Loke J, Le Caignec C, White S, Chin L, Friedman A, et al. Mutations in MAP3K1 cause 46,XY disorders of sex development and implicate a common signal transduction pathway in human testis determination. Am J Hum Genet. 2010 Dec 10; 87(6):898-904.

89 Loke J, Pearlman A, Radi O, Zuffardi O, Giussani U, Pallotta R, et al. Mutations in MAP3K1 tilt the balance from SOX9/FGF9 to WNT/ $\beta$ catenin signaling. Hum Mol Genet. $2014 \mathrm{Feb}$ 15;23(4):1073-83.

90 Chamberlin A, Huether R, Machado AZ, Groden M, Liu HM, Upadhyay K, et al. Mutations in MAP3K1 that cause 46,XY disorders of sex development disrupt distinct structural domains in the protein. Hum Mol Genet. 2019 May 15;28(10):1620-8.

91 Kim D, Choi JO, Fan C, Shearer RS, Sharif M, Busch P, et al. Homo-trimerization is essential for the transcription factor function of Myrf for oligodendrocyte differentiation. Nucleic Acids Res. 2017;45:5112-25.

92 Senoo H, Araki T, Fukuzawa M, Williams JG. A new kind of membrane-tethered eukaryotic transcription factor that shares an autoproteolytic processing mechanism with bacteriophage tail-spike proteins. J Cell Sci. 2013; 126:5247-58

93 Li Z, Park Y, Marcotte EM. A bacteriophage tailspike domain promotes self-cleavage of a human membrane-bound transcription factor, the myelin regulatory factor MYRF. PLoS Biol. 2013;11:e1001624.

94 Emery B, Agalliu D, Cahoy JD, Watkins TA, Dugas JC, Mulinyawe SB, et al. Myelin gene regulatory factor is a critical transcriptional regulator required for CNS myelination. Cell. 2009;138:172-85.

95 Garnai SJ, Brinkmeier ML, Emery B, Aleman TS, Pyle LC, Veleva-Rotse B, et al. Variants in myelin regulatory factor (MYRF) cause autosomal dominant and syndromic nanophthalmos in humans and retinal degeneration in mice. PLoS Genet. 2019;15:e1008130.
96 Hamanaka K, Takata A, Uchiyama Y, Miyatake S, Miyake N, Mitsuhashi S, et al. MYRF haploinsufficiency causes 46,XY and 46,XX disorders of sex development: bioinformatics consideration. Hum Mol Genet. 2019;28:2319-29.

97 Qi H, Yu L, Zhou X, Wynn J, Zhao H, Guo $\mathrm{Y}$, et al. De novo variants in congenital diaphragmatic hernia identify MYRF as a new syndrome and reveal genetic overlaps with other developmental disorders. PLoS Genet. 2018; 14:e1007822.

98 Rossetti LZ, Glinton K, Yuan B, Liu P, Pillai N, Mizerik E, et al. Review of the phenotypic spectrum associated with haploinsufficiency of MYRF. Am J Med Genet A. 2019;179: 1376-82.

99 Pinz H, Pyle LC, Li D, Izumi K, Skraban C, Tarpinian J, et al. De novo variants in Myelin regulatory factor (MYRF) as candidates of a new syndrome of cardiac and urogenital anomalies. Am J Med Genet A. 2018;176:96972 .

100 Janssens V, Goris J. Protein phosphatase 2A a highly regulated family of serine/threonine phosphatases implicated in cell growth and signalling. Biochem J. 2001 Feb 1;353(Pt 3): 417-39.

101 Katayama K, Yamaguchi M, Noguchi K Sugimoto Y. Protein phosphatase complex PP5/PPP2R3C dephosphorylates P-glycoprotein/ABCB1 and down-regulates the expression and function. Cancer Lett. 2014 Apr 1;345(1):124-31.

102 Reynhout S, Janssens V. Physiologic functions of PP2A: lessons from genetically modified mice. Biochim Biophys Acta Mol Cell Res. 2019 Jan;1866(1):31-50.

103 Guran T, Yesil G, Turan S, Atay Z, Bozkurtlar E, Aghayev A, et al. PPP2R3C gene variants cause syndromic 46,XY gonadal dysgenesis and impaired spermatogenesis in humans. Eur J Endocrinol. 2019 May 1; 180(5):291-309.

104 Malki S, Boizet-Bonhoure B, Poulat F. Shuttling of SOX proteins. Int J Biochem Cell Biol. 2010;42:411-6.

105 McElreavey K, Fellous M. Sex determination and the Y chromosome. Am J Med Genet. 1999 Dec 29;89(4):176-85.

106 McElreavy K, Vilain E, Abbas N, Costa JM, Souleyreau N, Kucheria K, et al. XY sex reversal associated with a deletion $5^{\prime}$ to the SRY "HMG box" in the testis-determining region. Proc Natl Acad Sci U S A. 1992;89: 11016-20.

107 McElreavey K, Vilain E, Barbaux S, Fuqua JS, Fechner PY, Souleyreau N, et al. Loss of sequences $3^{\prime}$ to the testis-determining gene, SRY, including the $\mathrm{Y}$ pseudoautosomal boundary associated with partial testicular determination. Proc Natl Acad Sci U S A. 1996;93:8590-4. 
108 Assumpção JG, Ferraz LF, Benedetti CE, Maciel-Guerra AT, Guerra G Jr, Marquesde-Faria AP, et al. A naturally occurring deletion in the SRY promoter region affecting the Sp1 binding site is associated with sex reversal. J Endocrinol Invest. 2005;28:651-6.

109 Foster JW, Dominguez-Steglich MA, Guioli S, Kwok C, Weller PA, Stevanović M, et al. Campomelic dysplasia and autosomal sex reversal caused by mutations in an SRY-related gene. Nature. 1994;372:525-30.

110 Katoh-Fukui Y, Igarashi M, Nagasaki K, Horikawa R, Nagai T, Tsuchiya T, et al. Testicular dysgenesis/regression without campomelic dysplasia in patients carrying missense mutations and upstream deletion of SOX9. Mol Genet Genomic Med. 2015;3: 550-7.

111 Sekido R, Lovell-Badge R. Sex determination involves synergistic action of SRY and SF1 on a specific Sox 9 enhancer. Nature. 2008 Jun 12;453(7197):930-4.

112 Gonen N, Quinn A, O’Neill HC, Koopman P, Lovell-Badge R. Correction: normal levels of Sox9 expression in the developing mouse testis depend on the TES/TESCO enhancer, but this does not act alone. PLoS Genet. 2017 Jan 3;13(1):e1006584.

113 Benko S, Gordon CT, Mallet D, Sreenivasan $\mathrm{R}$, Thauvin-Robinet $\mathrm{C}$, Brendehaug A, et al. Disruption of a long distance regulatory region upstream of SOX9 in isolated disorders of sex development. J Med Genet. 2011;48: 825-30.

114 Cox JJ, Willatt L, Homfray T, Woods CG. A SOX9 duplication and familial 46,XX developmental testicular disorder. N Engl J Med. 2011;364:91-3.

115 Vetro A, Dehghani MR, Kraoua L, Giorda R, Beri S, Cardarelli L, et al. Testis development in the absence of SRY: chromosomal rearrangements at SOX9 and SOX3. Eur J Hum Genet. 2015;23:1025-32.

116 Hyon C, Chantot-Bastaraud S, Harbuz R, Bhouri R, Perrot N, Peycelon M, et al. Refining the regulatory region upstream of SOX9 associated with 46,XX testicular disorders of Sex Development (DSD). Am J Med Genet A. $2015 ; 167: 1851-8$.

117 Ohnesorg T, van den Bergen JA, Belluoccio D, Shankara-Narayana N, Kean AM, Vasilaras A, et al. A duplication in a patient with 46,XX ovo-testicular disorder of sex development refines the SOX9 testis-specific regulatory region to $24 \mathrm{~kb}$. Clin Genet. 2017 Sep;92(3):347-9.

118 Kim GJ, Sock E, Buchberger A, Just W, Denzer F, Hoepffner F, et al. Copy number variation of two separate regulatory regions upstream of SOX9 causes isolated $46, \mathrm{XY}$ or 46,XX disorder of sex development. J Med Genet. 2015;52:240-7.

119 Croft B, Ohnesorg T, Hewitt J, Bowles J, Quinn A, Tan J, et al. Human sex reversal is caused by duplication or deletion of core enhancers upstream of SOX9. Nat Commun. 2018 Dec 14;9(1):5319.
120 Barrionuevo FJ, Hurtado A, Kim GJ, Real FM, Bakkali M, Kopp JL, et al. Sox9 and Sox8 protect the adult testis from male-to-female genetic reprogramming and complete degeneration. Elife. 2016 Jun 21;5:e15635.

121 Richardson N, Gillot I, Gregoire EP, Youssef SA, de Rooij D, de Bruin A, et al. Sox8 and Sox9 act redundantly for ovarian-to-testicular fate reprogramming in the absence of $\mathrm{R}$ spondin 1 in mouse sex reversals. Elife. 2020 May 26;9:e53972.

122 Lindeman RE, Murphy MW, Agrimson KS, Gewiss RL, Bardwell VJ, Gearhart MD, et al. The conserved sex regulator DMRT1 recruits SOX9 in sexual cell fate reprogramming. Nucleic Acids Res. 2021 Jun 21; 49(11):6144-64.

123 Portnoi MF, Dumargne MC, Rojo S, Witchel SF, Duncan AJ, Eozenou C, et al. Mutations involving the SRY-related gene SOX8 are associated with a spectrum of human reproductive anomalies. Hum Mol Genet. 2018 Apr 1;27(7):1228-40.

124 Erickson RP, Yatsenko SA, Larson K, Cheung SW. A case of agonadism, skeletal malformations, bicuspid aortic valve, and delayed development with a 16p13.3 duplication including GNG13 and SOX8 upstream enhancers: are either, both or neither involved in the phenotype? Mol Syndromol. 2011 Jan;1(4): 185-91.

125 Capel B. Vertebrate sex determination: evolutionary plasticity of a fundamental switch. Nat Rev Genet. 2017;18:675-89.

126 Elzaiat M, Todeschini AL, Caburet S, Veitia RA. The genetic make-up of ovarian development and function: the focus on the transcription factor FOXL2. Clin Genet. 2017; 91:173-82.

127 Chassot AA, Gillot I, Chaboissier MC. Rspondin1, WNT4, and the CTNNB1 signaling pathway: strict control over ovarian differentiation. Reproduction. 2014 Dec; 148(6):R97-110.

128 Biason-Lauber A, Chaboissier MC. Ovarian development and disease: the known and the unexpected. Semin Cell Dev Biol. 2015;45: 59-67.

129 Hao HX, Xie Y, Zhang Y, Charlat O, Oster E, Avello M, et al. ZNRF3 promotes Wnt receptor turnover in an R-spondin-sensitive manner. Nature. 2012;485:195-200.

130 Xie Y, Zamponi R, Charlat O, Ramones M, Swalley S, Jiang X, et al. Interaction with both ZNRF3 and LGR4 is required for the signalling activity of R-spondin. EMBO Rep. 2013;14:1120-6.

131 Harris A, Siggers P, Corrochano S, Warr N, Sagar D, Grimes DT, et al. ZNRF3 functions in mammalian sex determination by inhibiting canonical WNT signaling. Proc Natl Acad Sci U S A. 2018;115:5474-9.
132 Dupont S, Krust A, Gansmuller A, Dierich A, Chambon P, Mark M. Effect of single and compound knockouts of estrogen receptors alpha (ERalpha) and beta (ERbeta) on mouse reproductive phenotypes. Development. 2000;127:4277-91.

133 Krege JH, Hodgin JB, Couse JF, Enmark E Warner M, Mahler JF, et al. Generation and reproductive phenotypes of mice lacking estrogen receptor beta. Proc Natl Acad Sci USA. 1998;95:15677-82.

134 Antal MC, Krust A, Chambon P, Mark M. Sterility and absence of histopathological defects in nonreproductive organs of a mouse ERbeta-null mutant. Proc Natl Acad Sci U S A. 2008; 105:2433-8.

135 Lang-Muritano M, Sproll P, Wyss S, Kolly A, Hürlimann R, Konrad D, et al. Early-onset complete ovarian failure and lack of puberty in a woman with mutated Estrogen Receptor $\beta$ (ESR2). J Clin Endocrinol Metab. 2018; 103:3748-56.

136 Asadi M, Ghafouri-Fard S, Zare-Abdollahi D, Ebrahim-Habibi A, Matin N. Estrogen receptor mutation in a girl with primary amenorrhea. Clin Genet. 2013;83:497-8.

137 Baetens D, Güran T, Mendonca BB, Gomes NL, De Cauwer L, Peelman F, et al. Biallelic and monoallelic ESR2 variants associated with 46,XY disorders of sex development. Genet Med. 2018;20:717-27.

138 Tuzon CT, Rigueur D, Merrill AE. Nuclear fibroblast growth factor receptor signaling in skeletal development and disease. Curr Osteoporos Rep. 2019 Jun;17(3):138-46.

139 Kim Y, Bingham N, Sekido R, Parker KL Lovell-Badge R, Capel B. Fibroblast growth factor receptor 2 regulates proliferation and Sertoli differentiation during male sex determination. Proc Natl Acad Sci U S A. 2007 Oct 16;104(42):16558-63.

140 Bagheri-Fam S, Ono M, Li L, Zhao L, Ryan J, Lai R, et al. FGFR2 mutation in 46 ,XY sex reversal with craniosynostosis. Hum Mol Genet. 2015 Dec 1;24(23):6699-710.

141 Reardon W, Winter RM, Rutland P, Pulleyn LJ, Jones BM, Malcolm S. Mutations in the fibroblast growth factor receptor 2 gene cause Crouzon syndrome. Nat Genet. 1994 Sep;8(1):98-103.

142 Rutland P, Pulleyn LJ, Reardon W, Baraitser M, Hayward R, Jones B, et al. Identical mutations in the FGFR2 gene cause both Pfeiffer and Crouzon syndrome phenotypes. Nat Genet. 1995 Feb;9(2):173-6.

143 Kan SH, Elanko N, Johnson D, CornejoRoldan L, Cook J, Reich EW, et al. Genomic screening of fibroblast growth-factor receptor 2 reveals a wide spectrum of mutations in patients with syndromic craniosynostosis. Am J Hum Genet. 2002 Feb;70(2):472-86.

144 Tartaglia M, Di Rocco C, Lajeunie E, Valeri S, Velardi F, Battaglia PA. Jackson-Weiss syndrome: identification of two novel FGFR2 missense mutations shared with Crouzon and Pfeiffer craniosynostotic disorders. Hum Genet. 1997 Nov;101(1):47-50. 
145 Bagheri-Fam S, Chen H, Wilson S, Ayers K, Hughes J, Sloan-Bena F, et al. The gene encoding the ketogenic enzyme HMGCS2 displays a unique expression during gonad development in mice. PLoS One. 2020;15: e0227411.

146 Bouchard L, Robert MF, Vinarov D, Stanley CA, Thompson GN, Morris A, et al. Mitochondrial 3-hydroxy-3-methylglutaryl-CoA synthase deficiency: clinical course and description of causal mutations in two patients. Pediatr Res. 2001 Mar;49(3):326-31.

147 Birk OS, Casiano DE, Wassif CA, Cogliati T, Zhao L, Zhao Y, et al. The LIM homeobox gene Lhx9 is essential for mouse gonad formation. Nature. 2000 Feb 24;403(6772): 909-13.

148 Kunitomo M, Khokhar A, Kresge C, Edobor-Osula F, Pletcher BA. 46,XY DSD and limb abnormalities in a female with a de novo LHX9 missense mutation. Am J Med Genet A. 2020 Dec;182(12):2887-90.

149 Durkin ME, Ullmannova V, Guan M, Popescu NC. Deleted in liver cancer 3 (DLC3 ), a novel Rho GTPase-activating protein, is downregulated in cancer and inhibits tumor cell growth. Oncogene. 2007;26:4580-9.

150 Braun AC, Hendrick J, Eisler SA, Schmid S, Hausser A, Olayioye MA. The Rho-specific GAP protein DLC3 coordinates endocytic membrane trafficking. J Cell Sci. 2015;128: 1386-99.

151 Ilaslan E, Calvel P, Nowak D, Szarras-Czapnik M, Slowikowska-Hilczer J, Spik A, et al. A case of two sisters suffering from $46, \mathrm{XY}$ gonadal dysgenesis and carrying a mutation of a novel candidate sex-determining gene STARD8 on the X chromosome. Sex Dev. 2018;12:191-5.

152 Bednarek AK, Keck-Waggoner CL, Daniel RL, Laflin KJ, Bergsagel PL, Kiguchi K, et al. WWOX, the FRA16D gene, behaves as a suppressor of tumor growth. Cancer Res. 2001;61:8068-73.

153 White S, Hewitt J, Turbitt E, van der Zwan Y, Hersmus R, Drop S, et al. A multi-exon deletion within WWOX is associated with a 46,XY disorder of sex development. Eur J Hum Genet. 2012;20:348-51.

154 Mallaret M, Synofzik M, Lee J, Sagum CA, Mahajnah M, Sharkia R, et al. The tumour suppressor gene WWOX is mutated in autosomal recessive cerebellar ataxia with epilepsy and mental retardation. Brain. 2014;137: 411-9.

155 Mignot C, Lambert L, Pasquier L, Bienvenu T, Delahaye-Duriez A, Keren B, et al. WWOX-related encephalopathies: delineation of the phenotypical spectrum and emerging genotype-phenotype correlation. J Med Genet. 2015;52:61-70.

156 Tochigi Y, Takamatsu Y, Nakane J, Nakai R, Katayama K, Suzuki H. Loss of Wwox causes defective development of cerebral cortex with hypomyelination in a rat model of lethal dwarfism with epilepsy. Int J Mol Sci. 2019;20(14):3596.
157 He J, Zhou W, Shi J, Zhang B, Wang H. A Chinese patient with epilepsy and WWOX compound heterozygous mutations. Epileptic Disord. 2020;22:120-4.

158 Peter B, Dinu V, Liu L, Huentelman M, Naymik M, Lancaster $\mathrm{H}$, et al. Exome sequencing of two siblings with sporadic autism spectrum disorder and severe speech sound disorder suggests pleiotropic and complex effects. Behav Genet. 2019;49:399414.

159 Weisz-Hubshman M, Meirson H, Michaelson-Cohen R, Beeri R, Tzur S, Bormans C, et al. Novel WWOX deleterious variants cause early infantile epileptic encephalopathy, severe developmental delay and dysmorphism among Yemenite Jews. Eur J Paediatr Neurol. 2019;23:418-26.

160 Piard J, Hawkes L, Milh M, Villard L, Borgatti R, Romaniello R, et al. The phenotypic spectrum of WWOX-related disorders: 20 additional cases of WOREE syndrome and review of the literature. Genet Med. 2019;21: 1308-18.

161 Baronio F, Ortolano R, Menabò S, Cassio A, Baldazzi L, Di Natale V, et al. 46,XX DSD due to androgen excess in monogenic disorders of steroidogenesis: genetic, biochemical, and clinical features. Int J Mol Sci. 2019 Sep 17;20(18):4605.

162 Buonocore F, Maharaj A, Qamar Y, Koehler K, Suntharalingham JP, Chan LF, et al. Genetic analysis of pediatric primary adrenal insufficiency of unknown etiology: 25 years' experience in the UK. J Endocr Soc. 2021 May 11;5(8):bvab086.

163 Naasse Y, Bakhchane A, Charoute H, Jennane F, Bignon-Topalovic J, Malki A, et al. A novel homozygous missense mutation in the FU-CRD2 domain of the R-spondin1 gene associated with familial 46,XX DSD. Sex Dev. 2017;11(5-6):269-74.

164 Biason-Lauber A. WNT4, RSPO1, and FOXL2 in sex development. Semin Reprod Med. 2012 Oct;30(5):387-95.

165 Hastie ND. Wilms' tumour 1 (WT1) in development, homeostasis and disease. Development. 2017;144:2862-72.

166 Jaubert F, Vasiliu V, Patey-Mariaud de Serre $\mathrm{N}$, Auber F, Jeanpierre C, Gubler MC, et al. Gonad development in Drash and Frasier syndromes depends on WT1 mutations. Arkh Patol. 2003;65:40-4.

167 Barbaux S, Niaudet P, Gubler MC, Grünfeld JP, Jaubert F, Kuttenn F, et al. Donor splicesite mutations in WT1 are responsible for Frasier syndrome. Nat Genet. 1997;17:46770 .

168 Suri M, Kelehan P, O'neill D, Vadeyar S, Grant J, Ahmed SF, et al. WT1 mutations in Meacham syndrome suggest a coelomic mesothelial origin of the cardiac and diaphragmatic malformations. Am J Med Genet A. 2007;143A:2312-20.
169 Haning RV Jr, Chesney RW, Moorthy AV, Gilbert EF. A syndrome of chronic renal failure and $\mathrm{XY}$ gonadal dysgenesis in young phenotypic females without genital ambiguity. Am J Kidney Dis. 1985;6:40-8.

170 Jeanpierre C, Denamur E, Henry I, Cabanis MO, Luce S, Cécille A, et al. Identification of constitutional WT1 mutations, in patients with isolated diffuse mesangial sclerosis, and analysis of genotype/phenotype correlations by use of a computerized mutation database. Am J Hum Genet. 1998;62:824-33.

171 Ferrari MTM, Watanabe A, da Silva TE, Gomes NL, Batista RL, Nishi MY, et al. WT1 pathogenic variants are associated with a broad spectrum of differences in sex development phenotypes and heterogeneous progression of renal disease. Sex Dev. 2021 Aug 13:1-9. Epub ahead of print.

172 Gomes NL, de Paula LCP, Silva JM, Silva TE, Lerário AM, Nishi MY, et al. A 46,XX testicular disorder of sex development caused by a Wilms' tumour Factor-1 (WT1) pathogenic variant. Clin Genet. 2019 Jan;95(1): $172-6$.

173 Wu SP, Yu CT, Tsai SY, Tsai MJ. Choose your destiny: make a cell fate decision with COUP-TFII. J Steroid Biochem Mol Biol. 2016;157:7-12.

174 van den Driesche S, Walker M, McKinnell C, Scott HM, Eddie SL, Mitchell RT, et al. Proposed role for COUP-TFII in regulating fetal Leydig cell steroidogenesis, perturbation of which leads to masculinization disorders in rodents. PLoS One. 2012;7:e37064.

175 Lin FJ, You LR, Yu CT, Hsu WH, Tsai MJ, Tsai SY. Endocardial cushion morphogenesis and coronary vessel development require chicken ovalbumin upstream promotertranscription factor II. Arterioscler Thromb Vasc Biol. 2012;32:e135-46.

176 Mehanovic S, Mendoza-Villarroel RE, Viger RS, Tremblay JJ. The nuclear receptor COUP-TFII regulates Amhr2 gene transcription via a GC-rich promoter element in mouse Leydig cells. J Endocr Soc. 2019;3: 2236-57.

177 Mendoza-Villarroel RE, Robert NM, Martin LJ, Brousseau C, Tremblay JJ. The nuclear receptor NR2F2 activates star expression and steroidogenesis in mouse MA-10 and MLTC-1 Leydig cells. Biol Reprod. 2014;91: 26.

178 Qin J, Tsai MJ, Tsai SY. Essential roles of COUP-TFII in Leydig cell differentiation and male fertility. PLoS One. 2008;3:e3285.

179 Takamoto N, Kurihara I, Lee K, Demayo FJ Tsai MJ, Tsai SY. Haploinsufficiency of chicken ovalbumin upstream promoter transcription factor II in female reproduction. Mol Endocrinol. 2005;19:2299-308.

180 Zhao F, Franco HL, Rodriguez KF, Brown PR, Tsai MJ, Tsai SY, et al. Elimination of the male reproductive tract in the female embryo is promoted by COUP-TFII in mice. Science. 2017;357:717-20. 
181 Wang J, Abhinav P, Xu YJ, Li RG, Zhang M, Qiu XB, et al. NR2F2 loss-of-function mutation is responsible for congenital bicuspid aortic valve. Int J Mol Med. 2019;43:183946.

182 High FA, Bhayani P, Wilson JM, Bult CJ, Donahoe PK, Longoni M. De novo frameshift mutation in COUP-TFII (NR2F2) in human congenital diaphragmatic hernia. Am J Med Genet A. 2016;170:2457-61.

183 Al Turki S, Manickaraj AK, Mercer CL, Gerety SS, Hitz MP, Lindsay S, et al. Rare variants in NR2F2 cause congenital heart defects in humans. Am J Hum Genet. 2014;94:574-85.
184 Meinsohn MC, Smith OE, Bertolin K, Murphy $\mathrm{BD}$. The orphan nuclear receptors steroidogenic factor-1 and liver receptor homolog-1: structure, regulation, and essential roles in mammalian reproduction. Physiol Rev. 2019;99:1249-79.

185 Achermann JC, Schwabe J, Fairall L, Chatterjee K. Genetic disorders of nuclear receptors. J Clin Invest. 2017;127:1181-92.

186 Baetens D, Stoop H, Peelman F, Todeschini AL, Rosseel T, Coppieters F, et al. NR5A1 is a novel disease gene for 46,XX testicular and ovotesticular disorders of sex development. Genet Med. 2017;19:367-76.
187 Takasawa K, Igarashi M, Ono M, Takemoto A, Takada S, Yamataka A, et al. Phenotypic variation in 46,XX disorders of sex development due to the NR5A1 p.R92W variant: a sibling case report and literature review. Sex Dev. 2017;11:284-8.

188 Knarston IM, Robevska G, van den Bergen JA, Eggers S, Croft B, Yates J, et al. NR5A1 gene variants repress the ovarian-specific WNT signaling pathway in 46,XX disorders of sex development patients. Hum Mutat. 2019 Feb;40(2):207-16. 